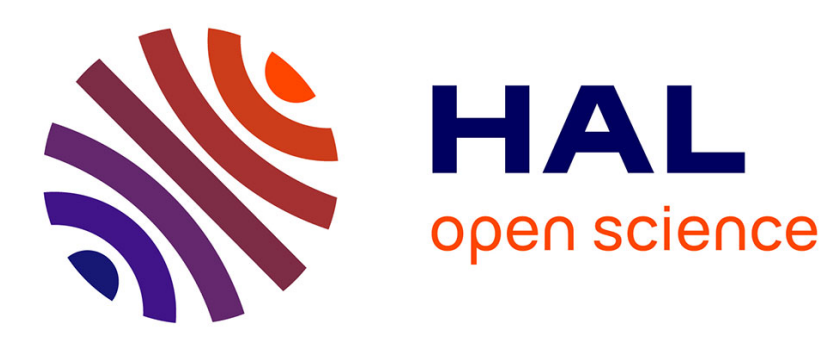

\title{
Detection of geomagnetic jerks using wavelet analysis
} Mioara Alexandrescu, Dominique Gibert, Gauthier Hulot, Jean-Louis Le

\author{
Mouël, Ginette Saracco
}

\section{To cite this version:}

Mioara Alexandrescu, Dominique Gibert, Gauthier Hulot, Jean-Louis Le Mouël, Ginette Saracco. Detection of geomagnetic jerks using wavelet analysis. Journal of Geophysical Research, 1995, 100 (B7), pp.12557 - 12572. 10.1029/95JB00314 . hal-01914560

\section{HAL Id: hal-01914560 https://hal.science/hal-01914560}

Submitted on 20 Sep 2019

HAL is a multi-disciplinary open access archive for the deposit and dissemination of scientific research documents, whether they are published or not. The documents may come from teaching and research institutions in France or abroad, or from public or private research centers.
L'archive ouverte pluridisciplinaire HAL, est destinée au dépôt et à la diffusion de documents scientifiques de niveau recherche, publiés ou non, émanant des établissements d'enseignement et de recherche français ou étrangers, des laboratoires publics ou privés. 


\title{
Detection of geomagnetic jerks using wavelet analysis
}

\author{
Mioara Alexandrescu, ${ }^{1}$ Dominique Gibert, ${ }^{2}$ Gauthier Hulot, ${ }^{1}$ \\ Jean-Louis Le Mouël, ${ }^{1}$ and Ginette Saracco ${ }^{2}$
}

\begin{abstract}
Wavelet analysis is applied to detect and characterize singular events, or singularities, or jerks, in the time series maxle of the last century monthly mean values of the east component of the geomagnetic field from European observatories. After choosing a well-adapted wavelet function, the analysis is first performed on synthetic series inclucling an "internal", or "main", signal made of smooth variation intervals separated by singular events with different "regularities", a white noise and an "external" signal maxle of the sum of a few liarmonics of a long-period variation (11 years). The signatures of the main, noise, and harmonic signals are studied and compared, and the conditions in which the singular events can be clearly isolated in the composite signal are elucidlated. Then we apply the method systematically to the real geomagnetic series (monthly means of $Y$ from European olsservatories) and show that five and only five remarkalsle events are found in 1901, 1913, 1925, 1969, and 1978. The characteristics of these singularities (in particular, homogeneity of some derived functions of the wavelet trausform over a large range of timescales) demonstrate that these events have a single source (of course, internal). Also the events are more singular than was previously supposed (their "regularity" is closer to 1.5 than to 2., inclicating that moninteger powers of time should be used in representing the time series between the jerks).
\end{abstract}

\section{Introduction}

The study of the time-varying geomagnetic: field olsserved at the Earth's surface is one of the best means of gaining information about the core dynamics. On timescales between a month and several centuries [Langel, 1987; Bloxham et al., 1989), the main contrilution to this field is the one, known as the "main tield", generated by the geodynamo process which takes plare within the core. The time variations of this field, the secular variation, mainly occur on clecarle and longer timescales, and its temporal spectrum was originally thought to be restricted to periods longer than 1 year (Currie [1966, 1968] suggested a cutoff at. 3.7 years), the shorter periods being attributed to exterual somrces. However, it had also been kuown for some time (as early as Fisk [1931]) that clear solar cycle (11 years) efferts the earlier spectral separation was at least partly incorrect. These solar cycle effects were investigated and confirmed by many authors, among them Courtillot and Le Mouel [1976a,b], who modeled the secular variation with a smooth parabolic trend and interpreted the residuals as solar-related effects. This model was consistent.

\footnotetext{
${ }^{1}$ Institut de Physique du Globe de Paris, France.

${ }^{2}$ Géosciences Rennes - CNRS/INSU, Université de Remues 1, France.
}

Copyright 1995 by the American Geopllysical Union.

Paper number 95JBou314.

0148-0227/95/95.JB-00314\$15.(0) with the 1947-1967 data, but difficulties arose with the data of the late 1960s, leading Courtillot et al. [1978] to use two successive parabolic trends instead of a single one. The change of trend occurred in 1970 and implied that contrary to prior belief, the main field could experience changes on timescales of 1 year or less. This discovery has since been confirmed by many authors (see the review by Courtillot and Le Mouel [1988] for a historical perspective), and the sudden change of trend is now known as the "1970 jerk" [Malin et al., 1983]. Subsecjuent studies have focused on the worldwide extent of the event [e.g., Chau et al., 1981; Le. Mouël et al., 1982; McLeod, 1992] and its origin [e.g., Alldredge, 1984; Nevanlinna, 1985; Backus et. al., 1987; Stewart and Whaler, 1992]. Spherical harmonic analysis [e.g., Malin and Hodder, 1982; Gubbins, 1984; McLeod, 1985, 1992] are in favor of an internal origin for the jerk, although these analyses do not allow separation of the main field from those induced in the conducting mantle by external sources.

In its present acceptance, the jerk is idealized as a sudden change in the slope of the secular variation defined as the first time derivative of the field. Alldredge [1984] underlined the possibility that some external signal might contribute to sharpen the change. Indeed, such a possibility cannot be excluded at once by referring to the previous splierical harmonic analysis since only a small contribution is required. Strong evidence has been presented against this view by Giavoret et ol . [1986] and Gubbins and Tomlinson [1986], who correlated as much as possible of the observed field with indexes monitoring the external activity. The removal 
of the corresponding contribution produced a smoother residual signal nevertheless displaying a very sharp jerk, implying an event duration shorter than a year.

Alldredge [1984] also discussed the identification of the jerk and argued that discontinuities in the second time derivative of the field are not determined by the analysis but constitute an a priori assumption. This prompted Backus and Hough [1985] and Backus et. al. [1987] to carry out some tests using much smoother functions to model the main field; they concluded that the jerk model leads to no better but no worse description of the data. In their review, Courtillot and Le Mouel [1988] give evidence for a slight advantage in favor of the jerk model which is now generally accepted as the working model for sudden events in the main field [Stewart, 1991]. Several other such events have been reported in the literature in 1913 [Ducruix et al., 1980], in 1978 [Gavoret et al., 1986; Gubbins and Tomlinson, 1986] and at possibly other epochs [e.g., Golovkov et al., 1989; Stewart, 1991; McLeod, 1992], but none have been scrutinized with as much intensity as the 1970 event.

The present paper intends to cast a completely different light on the subject. Admitting that sudden events of some unknown nature and at undefined dates may have occurred in the Earth's geomagnetic field, we wish to detect and characterize these events independently of any a priori information. Wavelet analysis is suited to this purpose since it can detect localized events without requiring a priori assumption. One further advantage of this analysis is its special sensitivity to localized events which we will refer to as singularities and define as cliscontinuities of some $\alpha$ derivative of the signal $(\alpha$, the regularity of the singularity, being not necessarily an integer). If such a singularity is included in the signal, wavelet analysis can detect it, give the time at which it, occurred, and provide a measurement of the regularity $\alpha$. Jerks, from now clefined as any singularity occurring within the main field, can be studied in a more general way.

The next section of this paper describes how the wavelet transform can be used to detect, and characterize singularities in time series when both noise and harmonic components are also present in the data. Detailed synthetic examples and numerous fignres should help the reader to evaluate the limits of the method. The following section presents the $Y$ monthly mean values analysis of the geomagnetic field series from $12 \mathrm{Eu}$ ropean observatories.

\section{Theoretical Background}

\section{Detection of Singularities With Wavelets}

In order to make this paper self-consistent, we only introduce the wavelet transform and recall its main properties with respect to the study of abrupt changes in signals [Grossmann, 1986; Grossmann et al., 1987]. More recent applications are given by Mallat and Huomig [1992], and references therein. The reader interested in the wavelet transform from a more general point of view is referred to Meyer [1990] and Daubechies [1992]. The. wavelet transform appeared as a section of mathematical analysis about, 10 years ago (see Meyer [1990] for a historical perspective) after the pioneering work of the geophysicist Jean Morlet [Goupillaud et al., 1984] and consists in expanding signals upon well-localized oscillating functions called "wavelets". The major characteristic of the wavelets is that all members of a given wavelet family are generated by translating and dilating a given initial wavelet, $\psi(t)$, called the "analyzing wavelet". The localization and characterization of singularities are best done with the continuous wavelet transform which is translation invariant and allows an optimal focusing on the sharp variations present in the signal.

We are interested in detecting singularities resulting from a discontinuity of the $\alpha$ th derivative of the signal, $\alpha$ being eventually a noninteger positive number. However, in practice, we will have to deal with "imperfect" data, and a number of difficulties will arise because actual data are both noisy and made not only of singularities. This will generate complications in the analysis procedure which we need to understand. It is not our aim to study this problem in the most general case, and we will make the assumption, realistic in geomagnetic studies, that the data series are the sum of a "main signal" including singularities whose regularities are to be found, of a "long-period harmonic signal", and of noise. The analyzed signal is then supposed to have the following canonical structure

$$
f(t)=\beta\left(t-t_{0}\right)_{+}^{\alpha \psi}+c(t)+n(t)
$$

where $c(t)$ is the long-period harmonic component, $n(t)$ is a stochastic process representing the noise present in the signal, and the distribution [Gel'fand and Shilov, 1962]

$$
\left(t-t_{0}\right)_{+}^{\alpha}=\left\{\begin{array}{ll}
0 & t \leq t_{0} \\
\left(t-t_{0}\right)^{\alpha} & t>t_{0}
\end{array},\right.
$$

represents the abrupt change of interest with a regularity $\alpha$ and localized at the time $t_{0}$. For instance, the singularity associated with the Heaviside function $H(t)$ has a regularity $\alpha=0$, while those associated with the Dirac distribution, $\delta(t)=(d / d t) H(t)$, and the ramp function, $r(t)=\int H(t) d t$ have a regularity $\alpha=-1$ and $\alpha=1$, respectively. A jerk (in its classical acceptance), $j(t)=\int r(t) d t$, is such that $\alpha=2$.

The formalism of the continuous wavelet transform was first introduced by Grossmann and Morlet [1984] and proved very powerful in characterizing the fine structure of multiscaled signals such as turbulence data [Muzy et al., 1991]. For the present study we shall define the wavelet transform under the form of the convolution product

$$
W f(t, a) \equiv f * \psi_{a}(t),
$$

where $\psi_{a}(t)=a^{-1} \psi(t / a)$ and $a>0$ is the dilation parameter. Provided the analyzing wavelet $\psi(t)$ is welllocalized around $t=0$ and has a vanishing integral, the transformation is invertible for a large class of signals $f(t)$. Owing to its intrinsic zooming property, the wavelet transform can be used as a mathematical mi- 
croscope both to detect singularities and to analyze the local regularity of signals. Grossmann [1986] gives an approach to detect singularities with a complex analytical wavelet and indicates that in the vincinity of an isolated sharp variation located at $t_{0}$, the lines in the timescale halfplane $(t, a)$ where the phase remains constant converge to the time $t_{0}$ when $a \downarrow 0$. Sharp variations can also be detected by using the modulus $|W f(t, a)|$ of the wavelet transform along these lines of constant phase. An alternative approach using real wavelets is followed by Mallat and Hwang [1992], who characterize singularities by studying the variations of the absolute value of the wavelet coefficients along lines of maxima. The method explained in the present paper is more reminiscent of this latter approach. The linearity of the wavelet transform gives

$$
\begin{aligned}
W f(t, a)= & \beta W\left[\left(t-t_{0}\right)_{+}^{\alpha}\right](t, a) \\
& +W c(t, a)+W n(t, a),
\end{aligned}
$$

and we will first explore the ways by which the information characterizing the singularity can be recovered from the wavelet transform $W\left(t-t_{0}\right)_{+}^{\alpha}$. The other two terms in (4) will be discussed later.

Let us consider that the analyzing wavelet can be expressed as the $n$th derivative of an everywhere positive, localized, and $C^{l>n}$ function $\phi(t)$. The wavelet transform of the singularity is

$$
\begin{aligned}
& \beta W\left[\left(t-t_{0}\right)_{+}^{\alpha x}\right](t, a) \\
= & \beta \frac{1}{a} \frac{d^{n}}{d(t / a)^{n}} \phi\left(\frac{t}{a}\right) *\left(t-t_{0}\right)_{+}^{\alpha x} \\
= & \beta a^{\alpha x} \frac{d^{n-\alpha x-1}}{d(t / a)^{n-c x-1}} \phi\left(\frac{t}{a}\right) * \frac{d^{\alpha+1}}{d t^{\alpha+1}}\left(t-t_{0}\right)_{+}^{\alpha x} \\
= & \Gamma(\alpha+1) \beta a^{\alpha x} \phi^{(n-\alpha-1)}\left(\frac{t}{a}\right) * \delta\left(t-t_{0}\right) \\
= & \Gamma(\alpha+1) \beta a^{\alpha} \phi^{(n-\alpha x-1)}\left(\frac{t-t_{0}}{a}\right),
\end{aligned}
$$

where we used the property [Gel'fand and Shilov, 1962]

$$
\frac{d^{\alpha+1}}{d t^{\alpha+1}}\left(t-t_{0}\right)_{+}^{\alpha}=\Gamma(\alpha+1) \delta\left(t-t_{0}\right),
$$

and assumed $n \geq \alpha+1$. Let us now suppose that, $\left|\phi^{(n-\alpha-1)}(t)\right|$ possesses $N_{l}$ maxima

$$
\left\{\phi_{\max , j} ; j=1, \cdots, N_{l}\right\}
$$

located at tlie times

$$
\left\{t_{\max , j} ; j=1, \cdots, N_{l}\right\} .
$$

The wavelet transform modulus $\left|W\left[\left(t-t_{0}\right)_{+}^{\alpha}\right](t, a)\right|$ possesses $N_{l}$ maxima located at the times

$$
\left\{a t_{\max , j}+t_{0} ; j=1, \cdots, N_{l}\right\}
$$

which converge to $t_{0}$ when $a \downarrow 0$. The maxima of the wavelet transform modulus arrange themselves onto $N_{l}$ lines

$$
\left\{t=a t_{\max , j}+t_{0} ; j=1, \cdots, N_{l}\right\} \text {, }
$$

which converge toward the time $t_{0}$ at which the singularity occurs. We can then define the "ridge function", $r_{j}$, as the absolute value of the wavelet transform along a given line of maxima:

$$
\begin{aligned}
r_{j}(a) & \equiv\left|\beta W\left[\left(t-t_{0}\right)_{+}^{\alpha}\right]\left(a t_{\max , j}+t_{0}, a\right)\right| \\
& =\Gamma(\alpha+1)|\beta| a^{\alpha} \phi_{\max , j} .
\end{aligned}
$$

Clearly,

$$
\ln r_{j}(\alpha)=\alpha \ln a+\ln \Gamma(\alpha+1)+\ln |\beta|+\ln \phi_{\max , j} .
$$

This formula shows that when plotted in a log-log diagram, the ridge function is a straight line whose slope equals the regularity $\alpha$. This result is derived by Mallat and Hwang [1992] in a slightly different way. This very distinctive feature arises because singularities are self-similar events on all timescales.

In the following numerical computations the input signal is evenly sampled with a 1-month interval, which we shall hereafter adopt as the unit of time, and local maxima are detected by direct comparison with the previous and next, sampling points. Strictly speaking, it is not permitted to discuss pure singularities for sampled signals, and we must instead say that at the sampling resolution, the signal behaves as if it had a discontinuity at $t_{0}$, although it is possible that it is continuous but has a sharp transition which is not visible at this finite resolution. We can only compute the wavelet transform at scales $a \geq a_{\min }$, where $a_{\min }$ must be such that the narrowest wavelet is properly sampled. On the other hand, the finite length of the signals limits the maximum scale $a_{\max }$ available. In practice, this upper boundary is controlled both by the limit beyond which convolutional edge effects become intolerable and by the proximity of the different singularities present in the signals. The sampling along the dilation axis is not governed by any law for this kind of applications of the wavelet transform. It must be both fine enough to allow for an easy tracking of the lines of maxima and coarse enough to reduce the computational burden. In the present stucly, we exponentially sampled the dilation axis with a multiplicity of 20 samples per octave.

If we want to estimate regularities smaller than an integer $m$, we need a wavelet with at least $m$ vanishing moments (see equation (5)). A wavelet with $m$ vanisling moments has at least $m+1$ extrema. In order to both reduce the amount of computation and improve the readability of the results, we would like to minimize the number of maxima required to detect the interesting abrupt changes in the signal. We must choose a wavelet with as few as possible vanishing moments compatible with the maximum regularity we look for. The results presented in this study were obtained with the analyzing wavelet

$$
\psi(t)=\frac{d^{3}}{d t^{3}} \exp \left(-\frac{t^{2}}{2}\right)
$$

shown on Figure 1. Since it possesses three vanishing moments, included the zero-order one, it allows the 


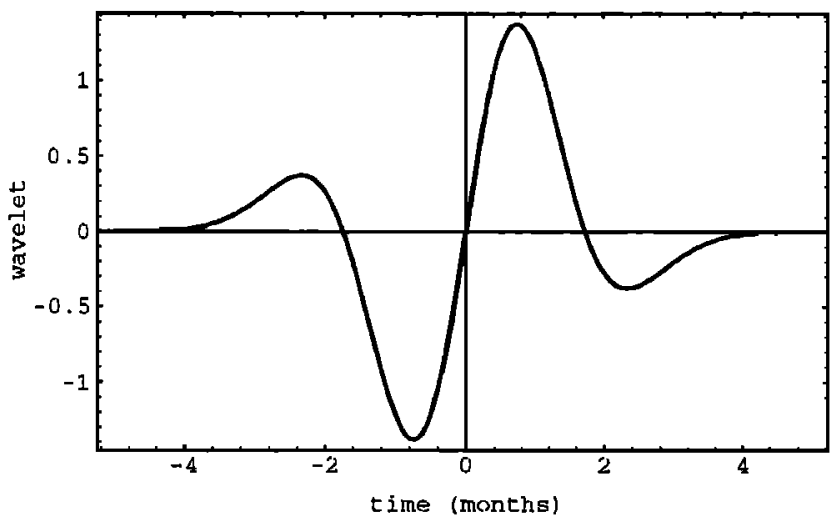

Figure 1. Graph of the analyzing wavelet used in the present study. This function is the third derivative of a Gaussian (see equation (13)) and possesses three vanishing moments.

study of singularities with $\alpha<3$. Its Fourier transform (Figure 2),

$$
\widehat{\psi}(u)=-i(2 \pi)^{7 / 2} u^{3} \exp \left(-2 \pi^{2} u^{2}\right),
$$

possesses extrema at $u_{m}= \pm \sqrt{3} / 2 \pi$ and has no significant energy beyond a cutoff frequency $u_{c}=0.7$ so the wavelets can be sampled at a unit time interval without aliasing error for $a \geq a_{\min } \geq 1.4$. The choice for the analyzing wavelet (13) leads to simple algebraic expressions, but many other analyzing wavelets conld be used. The results obtained are insensitive to the particular choice as long as the wavelet possesses a sufficient. number of vanishing moments [e.g., Bacry et al., 1991].

Let us now look at the way this machinery works by examining the case study of a canonical signal made up of several singularities (Figure 3 ). The modulus of the wavelet transform of this test signal is shown on Figure 4a. Since the wavelet coefficients vary in a wide range, a gray scale adapted to the whole $|W f(t, a)|$ map cannot enable an easy view of the lines of maxima over the entire $\left[a_{\min }, a_{\max }\right]$ range. Following Argoul et al. [1989], we chose to adapt the gray scale independently for each horizontal line of the $|W f(t, a)|$ map. This allows a

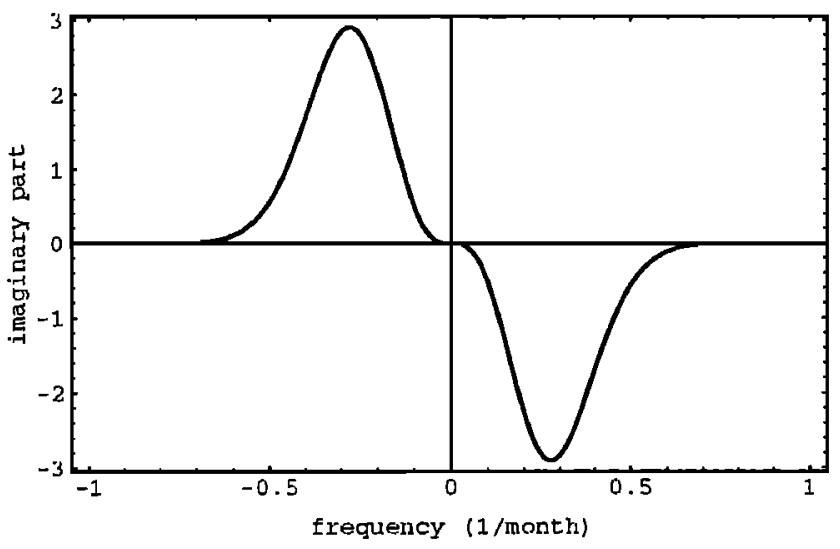

Figure 2. Graph of the Fourier transform of the analyzing wavelet (see equation (14)) shown in Figure 1.

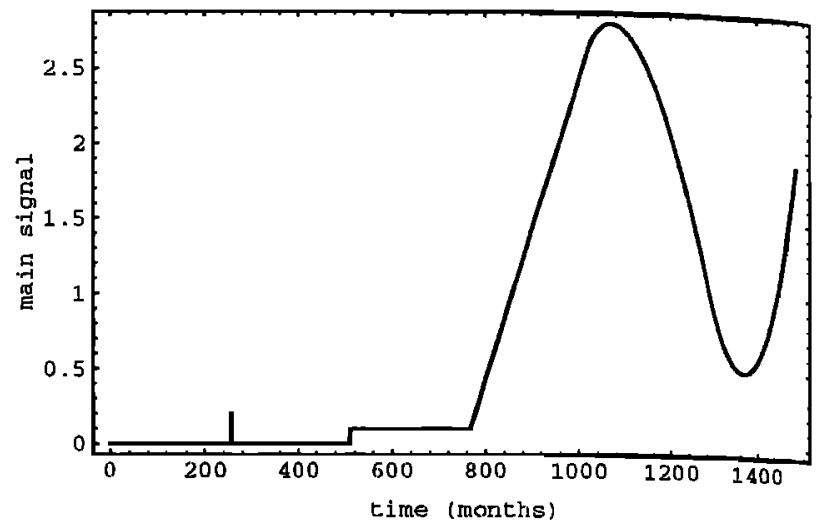

Figure 3. Synthetic signal with various singularities. This signal was created according to $s(t)=0.2 \delta\left(t-t_{1}\right)+0.1 H\left(t-t_{2}\right)+0.01 r\left(t-t_{3}\right)$ $-0.001\left(t-t_{4}\right)_{+}^{3 / 2}+0.0001 j\left(t-t_{5}\right)$ and possesses singularities with $\alpha=-1,0,1,3 / 2$, and 2 at $\left\{t_{1}, t_{2}, t_{3}, t_{4}, t_{5}\right\}=\{255,511,767,1023,1279\}$, respectively.

better tracking of all lines of maxima over the whole dilation range. All wavelet transforms are displayed according to this setting. As predicted by the theory, the lines of maxima converge toward the locations of the abrupt change when the dilation parameter decreases (Figure 5). The number $N_{l}$ of lines of maxima attached to a given singularity clecreases when its regularity increases. For a Dirac singularity,

$$
\begin{aligned}
W \delta(t, a) & =\delta(t) * \psi_{a}(t) \\
& =a^{-1} \psi\left(\frac{t}{a}\right),
\end{aligned}
$$

and $N_{l}=4$, the number of extrema of the analyzing wavelet (Figure 1). For a jerk,

$$
\begin{aligned}
W j(t, a) & =j(t) * \psi_{a}(t) \\
& =a^{-1} j(t) * \frac{d^{3}}{d(t / a)^{3}} \exp \left(-\frac{t^{2}}{2 a^{2}}\right) \\
& =a^{2} \frac{d^{3}}{d t^{3}} j(t) * \exp \left(-\frac{t^{2}}{2 a^{2}}\right) \\
& =a^{2} \delta(t) * \exp \left(-\frac{t^{2}}{2 a^{2}}\right) \\
& =a^{2} \exp \left(-\frac{t^{2}}{2 a^{2}}\right)
\end{aligned}
$$

and $N_{l}=1$. Generalizing these calculus to the case of noninteger $\alpha$ would involve the use of more sophisticated noninteger derivatives of functions. We made a practical investigation of this case and found that the number of lines of maxima corresponding to a noninteger regularity ecpuals the number of such lines associated with the nearest smaller integer regularity $N_{l}(\alpha \geq-1)=N_{l}(\max \{n \in \mathcal{Z} ; n \leq \alpha\})$. An example is given by the sharp variatiou located at $t=1023$ on Figure 5. It is such that $\alpha=1.5$ and is associated 

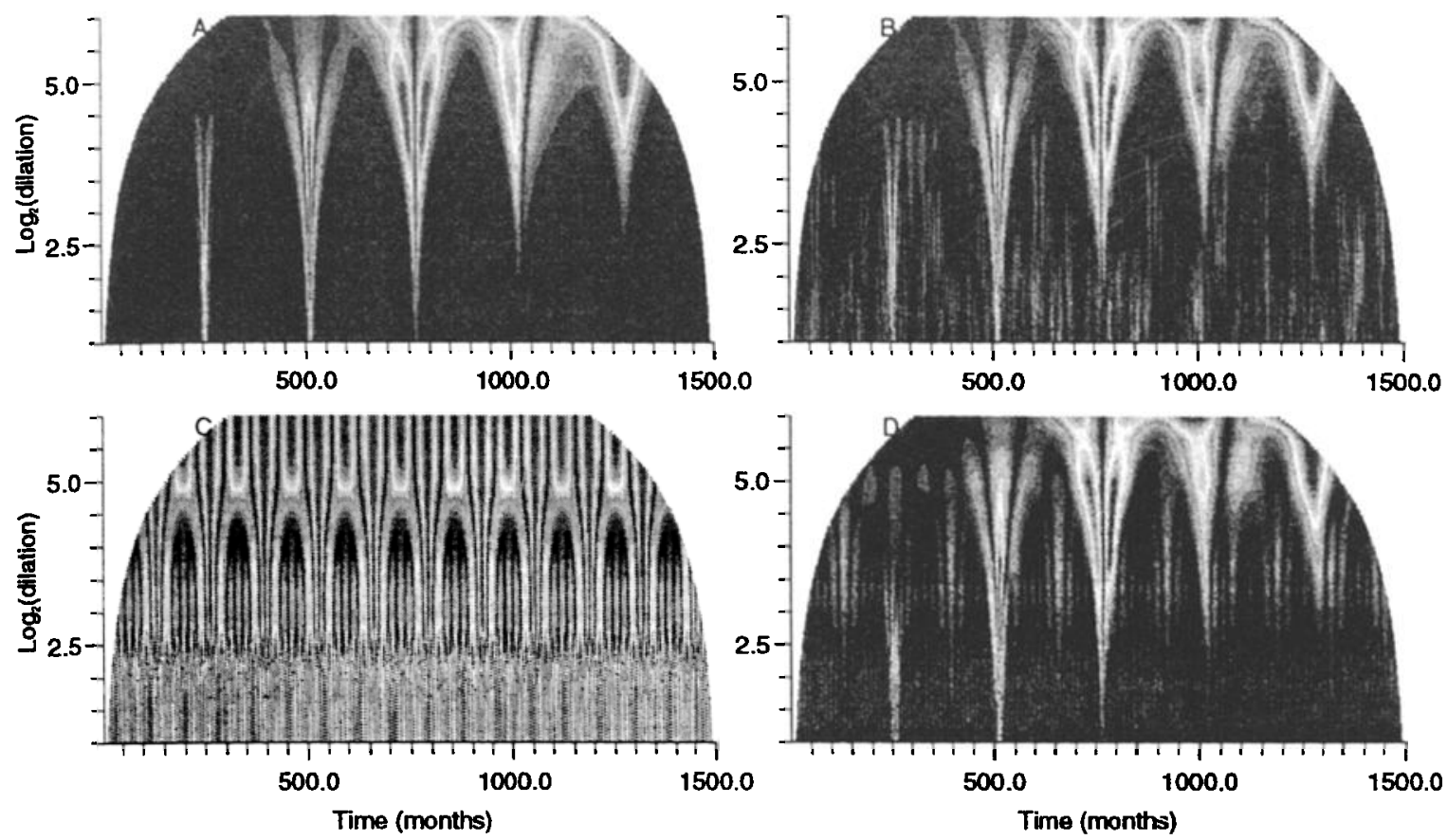

Figure 4. Absolute value of the wavelet transforms of the synthetic signals used to check our methodology. The dilations range from $a_{\min }=2$ to $a_{\max }=64$. Largest values are in light gray and smallest in heavy gray. (a) Wavelet transform of the "main" synthetic signal shown on Figure 3 and made up of pure singularities. Notice the symmetry of the lines of maxima excepted for those attached to the singularity with the non-integer regularity $\alpha=3 / 2$ at $t_{4}=1023$. (b) Wavelet transform of the "main" synthetic signal shown on Figure 3 polluted with a Gaussian white noise with a standard deviation $\sigma_{n}^{2}=10^{-2}$. Notice the appearance of numerous lines of maxima produced by the noise. (c) Wavelet transform of the composite harmonic signal shown on Figure 9. (d) Wavelet transform of the synthetic signal shown on Figure 12 and equal to the sum of the "main" signal with the composite harmonir signal.

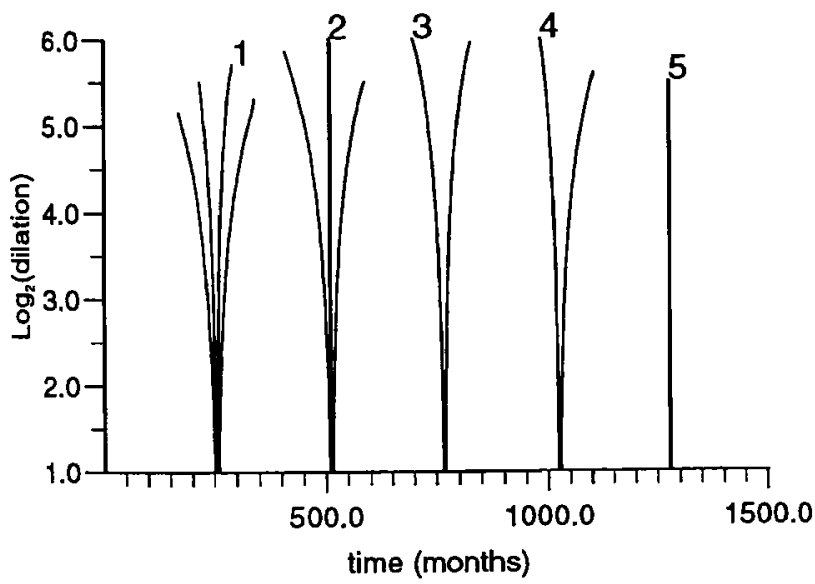

Figure 5. Lines of maxima extracted from the wavelet. transform (Figure 4a) of the synthetic signal shown on Figure 3. Notice that the number of lines attached to a given singularity decreases when the regularity increases. Lines attached to the singularity with a noninteger regularity are nonsymmetrical (see text for details). with two lines of maxima as in the case of the singularity located at $t=767$ for which $\alpha=1$. The number of lines of maxima is then an indicator for the possible range of the regularity. Various ridge functions are shown on Figure 6, and one can check that the slopes are in agreement with the theoretical regularities of the singularities present in the synthetic signal.

\section{Adding Noise}

In this section, we address the influence of noise. The wavelet transform $W n(t, a)$ of the noise is a stochastic process, and assuming that the imput noise is white Gaussian with zero mean and variance $\sigma_{n}^{2}$, the linearity of the wavelet transform ensures that this process is also Gaussian with a variance

$$
\begin{aligned}
\sigma_{W n}^{2}(a) & =\sigma_{n}^{2} \int_{-\infty}^{+\infty} \psi_{a}^{2}(t) d t \\
& =\frac{\sigma_{n}^{2}}{a} \int_{-\infty}^{+\infty} \psi^{2}(\xi) d \xi \\
& =\frac{15 \sqrt{\pi}}{8} \times \frac{\sigma_{n}^{2}}{a} .
\end{aligned}
$$

This expression shows that the variance of $W n(t, a)$, which is also the variance of $W f(t, a)$, decreases like 

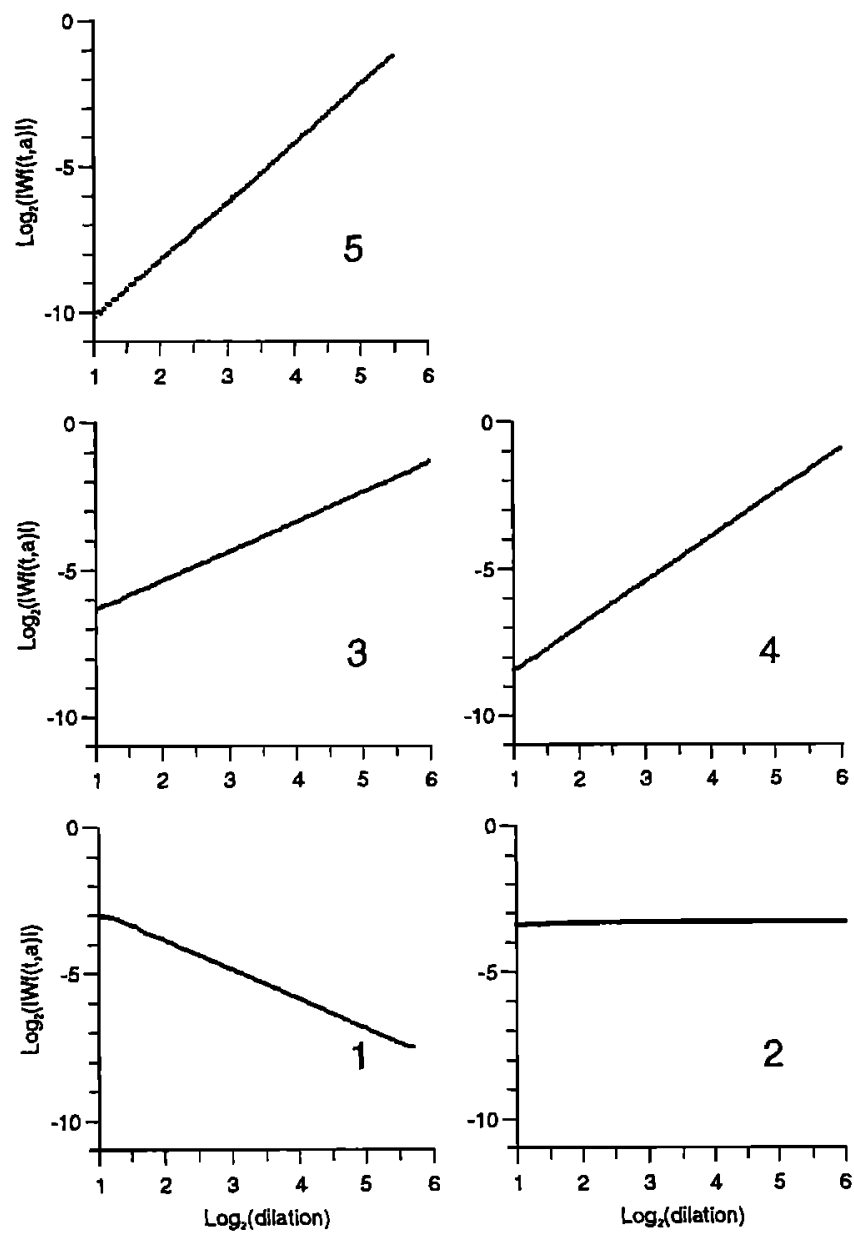

Figure 6. Log-log plots of the ridge functions associated witl the labeled lines of maxima shown on Figure 5 . These curves accurately fit straight lines whose slopes are the theoretical regularities of the abrupt changes present in the synthetic signal shown in Figure 3.

$a^{-1}$ when the dilation $a$ increases. Therefore, as $a$ increases, the typical amplitude of the noise decreases like $a^{-1 / 2}$ and in the vincinity of a singularity with $\alpha \geq$ $-1 / 2$, the signal-to-noise ratio increases like $a^{\alpha+1 / 2}$. Eventually,

$$
W f\left(t, a \gg a_{c_{c}}\right) \simeq W\left[\left(t-t_{0}\right)_{+}^{c^{x}}\right]\left(t, a \gg a_{c}\right),
$$

where $a_{c}$ is a corner dilation corresponding to a signalto-noise ratio of the order of 1 . The precise value of this corner dilation depends of course on the variance $\sigma_{n}^{2}$, the regularity and strength of the singularity. Conversely, for small dilations, the variance will be large and

$$
W f\left(t, a \ll a_{c}\right) \simeq W n\left(t, a \ll a_{c}\right) .
$$

We then expect a twofold behavior for the lines of maxima and ridge functions corresponding to a singularity with $\alpha>-1 / 2$ : they will be essentially controlled by the noise for small dilations and by the deterministic signal for large ones. In the case of a singularity with regularity $\alpha<-1 / 2$ (such as a Dirac singularity) the conclusion is just the opposite: noise will be responsible for the behavior of the lines of maxima and ridge functions when the dilation is large, and the deterministic signal will show up only for small dilations. Of course, in both cases, the transition between the deterministic and noise-related behaviors will be all the clearer that $\alpha$ is more different from the critical value $\alpha=-1 / 2$. Figure $4 \mathrm{~b}$ shows the wavelet transform of the synthetic signal after addition of a Gaussian white noise with $\sigma_{n}^{2}=10^{-4}$ (of the order of the noise found in real data). Figures 7 and 8 show the associated lines of maxima and ridge functions. As can be seen, although a very large number of new lines of maxima arise, almost all of these lines fail to reach dilation value $2^{5}$. In addition, all corresponding new ridge functions have smaller absolute values than those associated with the singularities (see, for instance, ridge function 6 on Figure 8). In fact, the main effect of noise appears to be the distortion of the still detectable singularity-related lines of maxima and ridge functions. The weakest of these can be seriously perturbed, as is the case with some of the lines associated with the singularities at times $t_{1}=255$ and $t_{4}=1023$ (Figure 7) and as will also usually be the case with the weak additional line of maxima we expect to find when the regularity parameter $\alpha$ is not far below an integer value (the closer $\alpha$ is below such a value, the weaker is the additional line). There will nevertlueless always remain at least one main line of maxima and the corresponding ridge function which will follow a pattern that can easily be related to the theoretical considerations seen before. For instance, this pattern is very clear for ridge functions 3,4 and 5 corresponding to $\alpha=1,1.5,2$. A corner dilation $a_{c}$ can indeed be found, the noisy part of the functions having the expected shaky negative slope of about $-1 / 2$, while the part controlled by the deterministic component is only very slightly perturbed. Ridge functions 1 and 2 illnstrate two situations when the scale of dilations used for the computation of the wavelet transform is not wide enough to clearly detect the corner dilations. In the case of ridge function 2 , the stable slope which is different from $-1 / 2$ indicates that we are clealing with the deterministic part of the function and that, the cormer dilation is larger than $2^{5}$. The shaky but close to -1

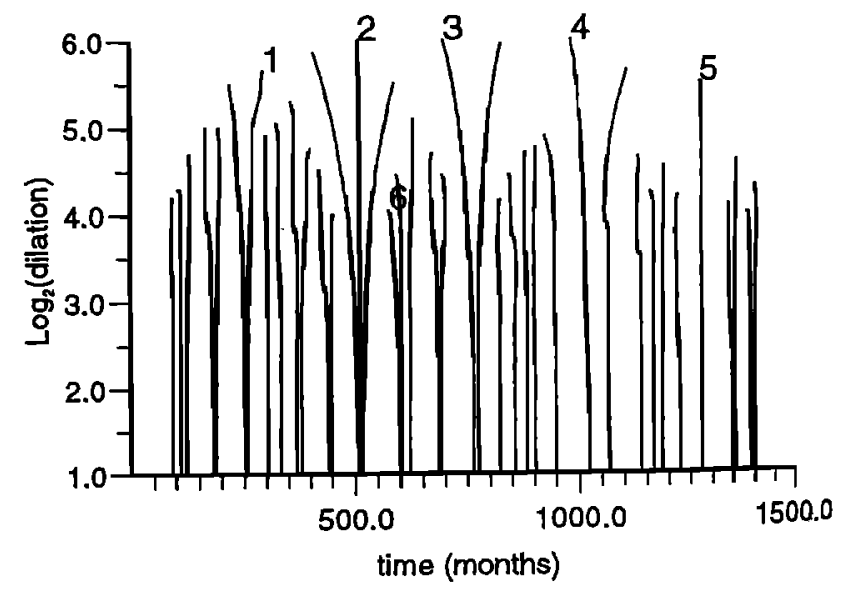

Figure 7. Lines of maxima extracted from the wavelet transform (Figure $4 \mathrm{~b}$ ) of the noisy synthetic signal. Only the longest lines are drawn. 

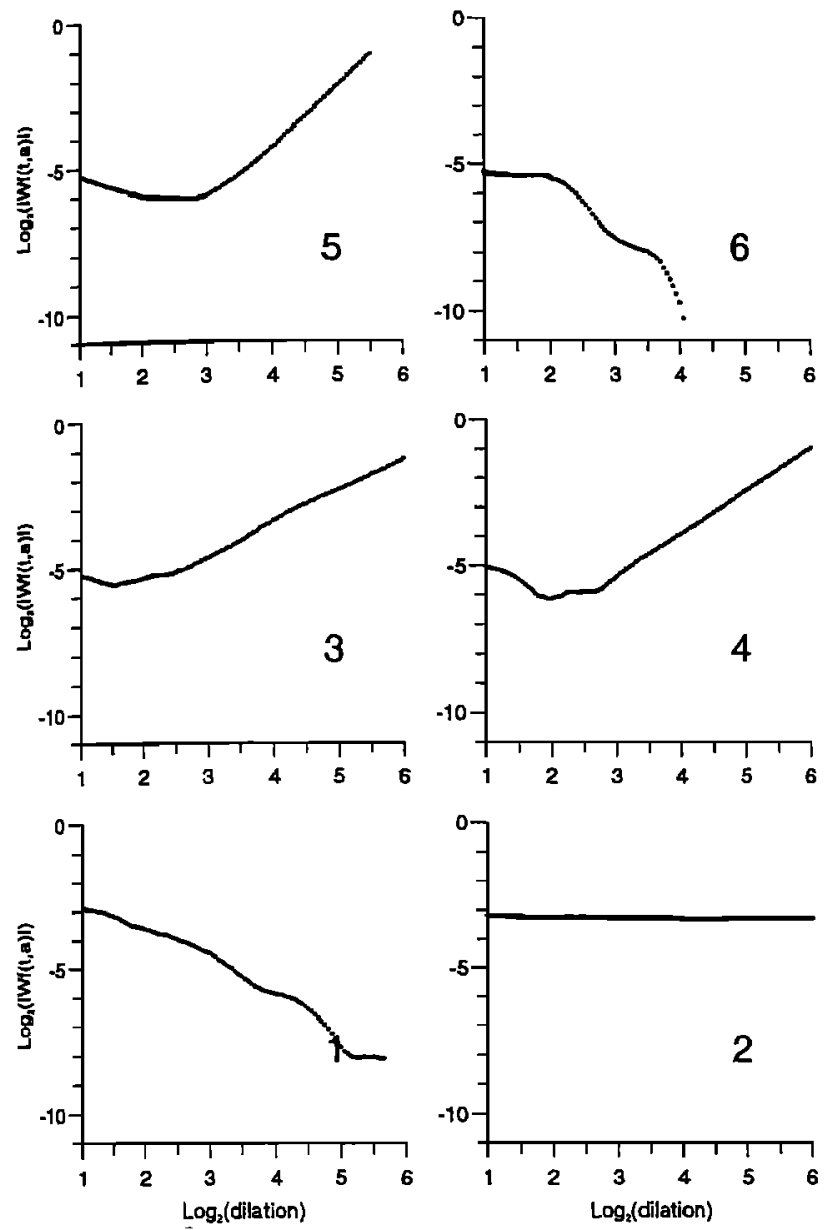

Figure 8. Log-log plots of the ridge functions associated with the labeled lines of maxima shown on Figure 7 extracted from the wavelet transform (Figure $4 \mathrm{~b}$ ) of the noisy signal. The slopes found for lines $1,2,3,4$, and 5 are $\alpha=-1.18$ and -0.02 for $a \geq 2$ and $\alpha=1.12$, 1.47 , and 2.0 for $a \geq 2^{3}$, respectively. Ridge function 6 is entirely due to noise.

slope of the ridge function 1 corresponds to the situation when we observe the transition between the two deterministic and noise-related behaviors. In such a situation it will not be possible to derive a precise value for the regularity of the singularity. From the previous considerations we conclude that in practice one should not rely on the number of lines of maxima to estimate the regularity of a singularity. Rather, and as was already suggested in the previous section, one should only consider the most significant lines of maxima, focus on the behavior of the corresponding ridge functions, look for clear linear portions, and find out the values of the corresponding slopes. This then allows a proper estimate of the regularity of the singularity, assuming the signal is made of pure singularities and noise. This, however, is not exactly the case since long-period harmonic components contribute to the signal in geomagnetic series. We therefore now need investigate the effect. of adding such components to the main signal.

\section{Adding Long-Period Harmonic Components}

Let us now consider the case when $c(t)$ (recall equation (1)) is made of long-period harmonic components. The transform of a pure sinusoidal component reads

$$
\begin{aligned}
& W\left[\sin \frac{2 \pi t}{T}\right](t, a) \\
= & (2 \pi)^{7 / 2}\left(\frac{a}{T}\right)^{3} \exp \left(-\frac{2 \pi^{2} a^{2}}{T^{2}}\right) \cos \frac{2 \pi t}{T},
\end{aligned}
$$

and its modulus is maximum for

$$
a_{T}=T \sqrt{3} / 2 \pi
$$

along any line $t=$ const in the $(t, a)$ plane. Equation (21) allows for a correspondence between dilations, $\iota_{T}$, and harmonic frequencies, $1 / T$. As a first step, we analyze a composite signal (Figure 9 ) made of harmonic components with periods $T=11,5.5,3.7$, and 1 years corresponding to $\log _{2} a_{T}=5.2,4.2,3.6$, and 1.73 , respectively, this choice being motivated by the geomagnetic data we will analyze next. Also, the relative phasing between the four sinusoids has been adapted to give the composite signal the appearance of a saw tooth signal. This choice has been made in order to analyze the most singular signal possible which can be created with the four harmonic components cited above. The wavelet transform (Figure 4c) of this signal is an interference. pattern between the different transforms (20), although complex this pattern possesses lines of maxima with a typical fork-shaped motif in the $|W c(t, a)|$ map (Figure 10). The ridge functions of these lines often possess maxima very near the $a_{T} \mathrm{~s}$, although these maxima may interfere constructively to give "plateaus"(Figure 11). In any case, and as could easily be expected from ecpuation (20), all ridge functions sharply decrease beyond the dilation $a_{T}=2^{5.2}$, corresponding to the largest period present in the composite signal, a distinctively different behavior from the one (linear in a log-log scale) we previously described for the ridge functions associated with singularities.

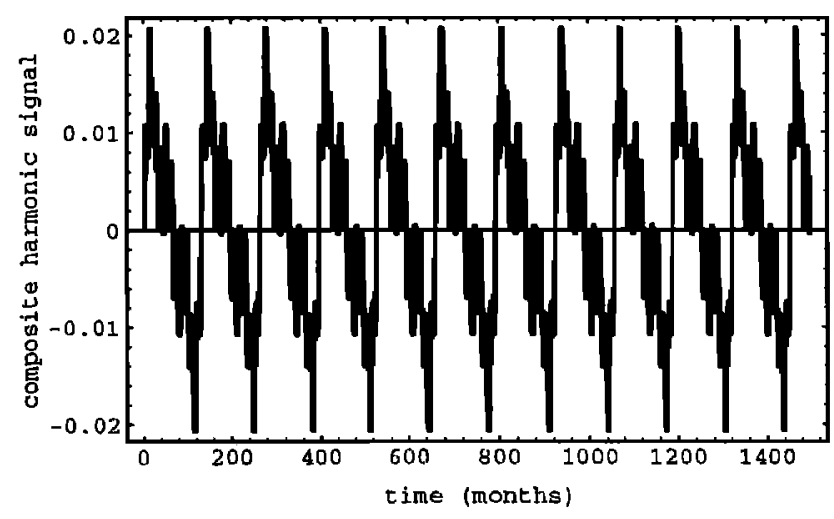

Figure 9. Composite harmonic signal made up of four sinusoids with periods $T=11,5.5,3.7$, and 1 year and respective amplitudes $A_{T}=0.01,0.005,0.005$, and 0.005 . 


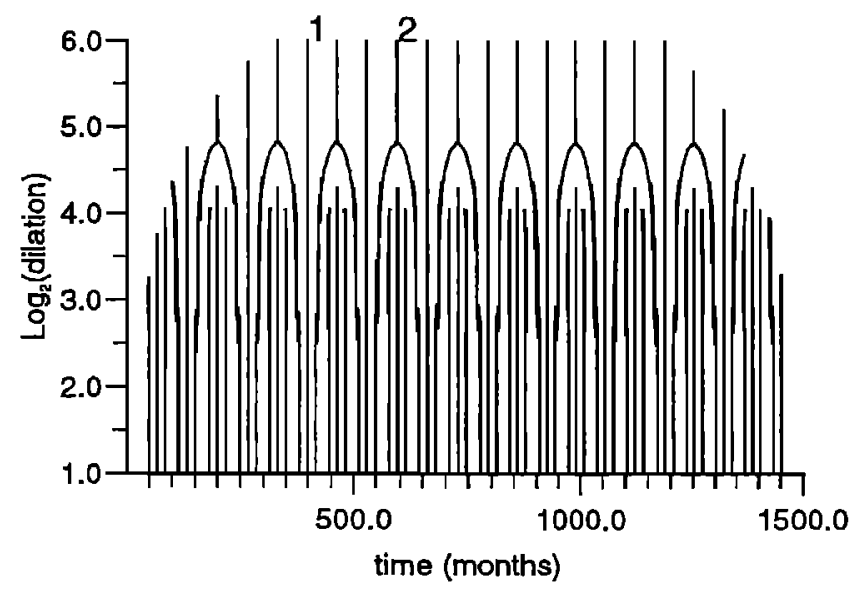

Figure 10. Lines of maxima of the wavelet transform modulus (Figure 4c) of the composite harmonic signal (Figure 9).

The possibility of recovering information about the singularities in the main signal when it is perturbed by the harmonic signal can then be investigated by analyzing the superimposition of the two signals (Figure 12). Relative amplitudes are conformed to real geomagnetic data. A quick glance at Figure 14 in view of Figures 6 and 11 suggests a rather straightforward identification of the various features due to the main signal and the harmonic signal, respectively. A similar identification is also suggested for the lines of maxima (compare Figures 5,10 , and 13 ). It is likely that those which overlap on the typical fork-shaped motif are related to the harmonic signal, whereas those which have "deep" roots are related to the main signal. The interartion between the main signal and the harmonic signal leads to the. vanishing of several maxima lines, while some remaining lines of maxima branch from a line associated with one signal to a line associated with the other signal. Identification and interpretation of the lines of maxima in the combined signal must therefore be carried out with some care.

\section{Classification of the Synthetic Ridge Functions}

The previous synthetic examples show that the singularities, random noises and harmonic components can
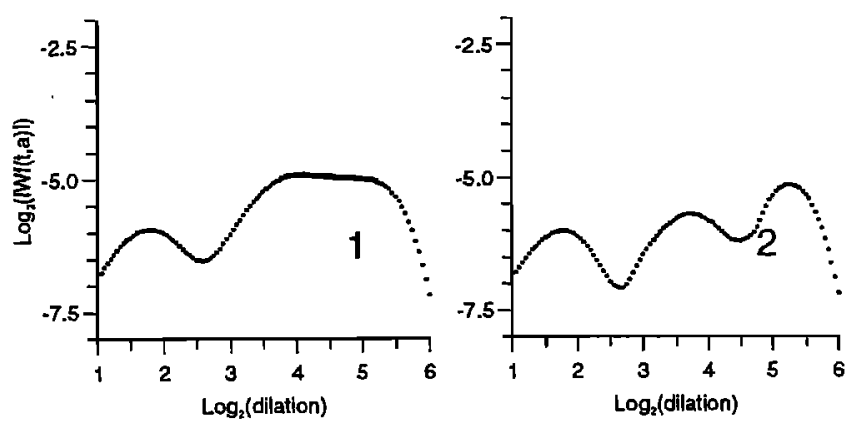

Figure 11. Log-log plots of the ridge functions associated with the labeled lines of maxima shown on Figure 10.

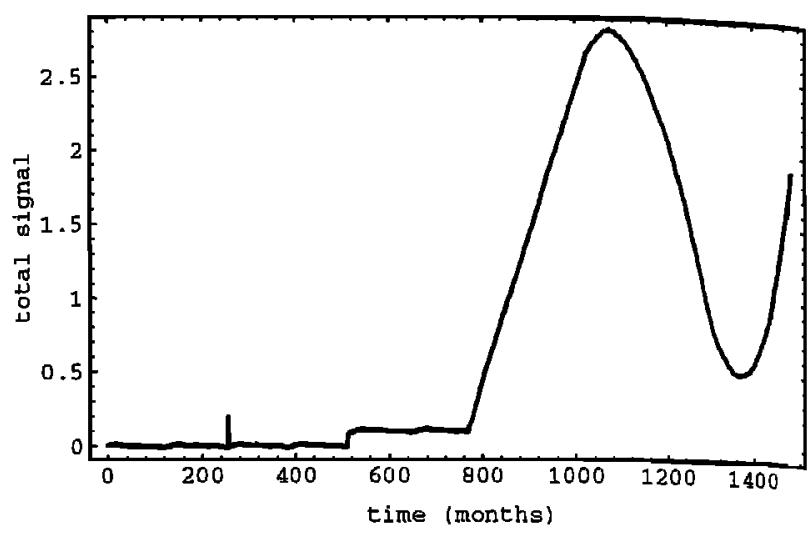

Figure 12. Signal made up of the sum of the main signal (Figure 3) with the composite harmonic signal (Figure 9).

produce ridge functions whose more or less complicated shapes depend on the relative balance between these three kinds of signals forming the data (equation (1)). We now need to elaborate some criteria to safely deride whether or not a given ridge function is mainly created by a singularity. Relying on roles played by the signal components considered in the previous three sections, the ridge functions can be classified into three types:

Type 1 is for ridge functions displaying a positive linear trend (i.e. $\alpha>0$ ) for most of the dilation range and especially for $a>2^{5.2}$. A limited small-dilation range can eventually be controlled by the harmonic signal (as illustrated on Figure 14 by the ridge functions 9, 10, 13, 14 , and 16 , when no noise is present), the randon noise (for ridges 3, 4, and 5 in Figure 8), or more generally by a combination of the two. Ridge functions of type 1 may safely be considered as mainly due to singularities.

Type 2 corresponds to ridge functions having a wobbling pattern (cases 1, 4, 8, 11, and 15 in Figure 14) and possibly displaying a sharp decrease for $a>2^{5.2}$ (cases 4,8 , and 11 in Figure 14), typical of ridge functions caused by harmonic components (see ecquation (20)).

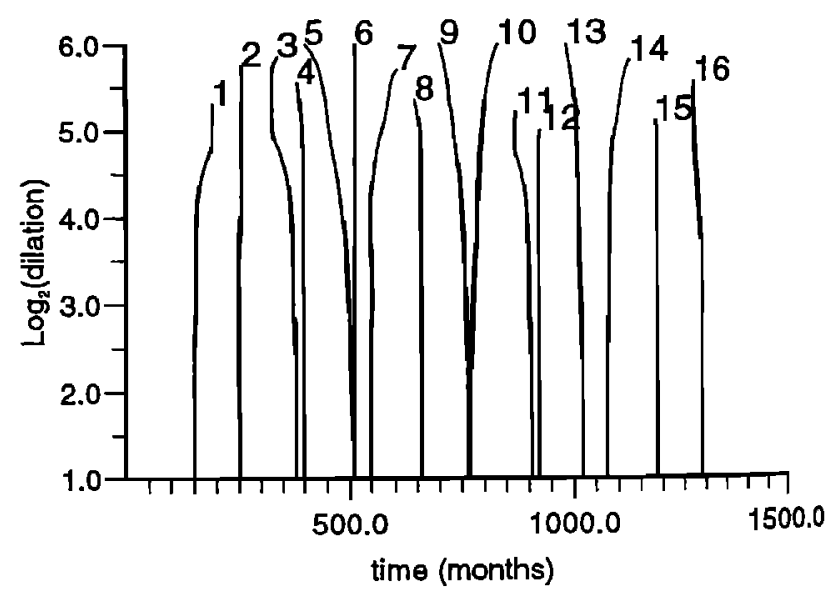

Figure 13. Lines of maxima of the wavelet transform modulus (Figure 4d) of the signal made up of the stlperimposition of the main signal and of the composite harmonic signal (Figure 12). 

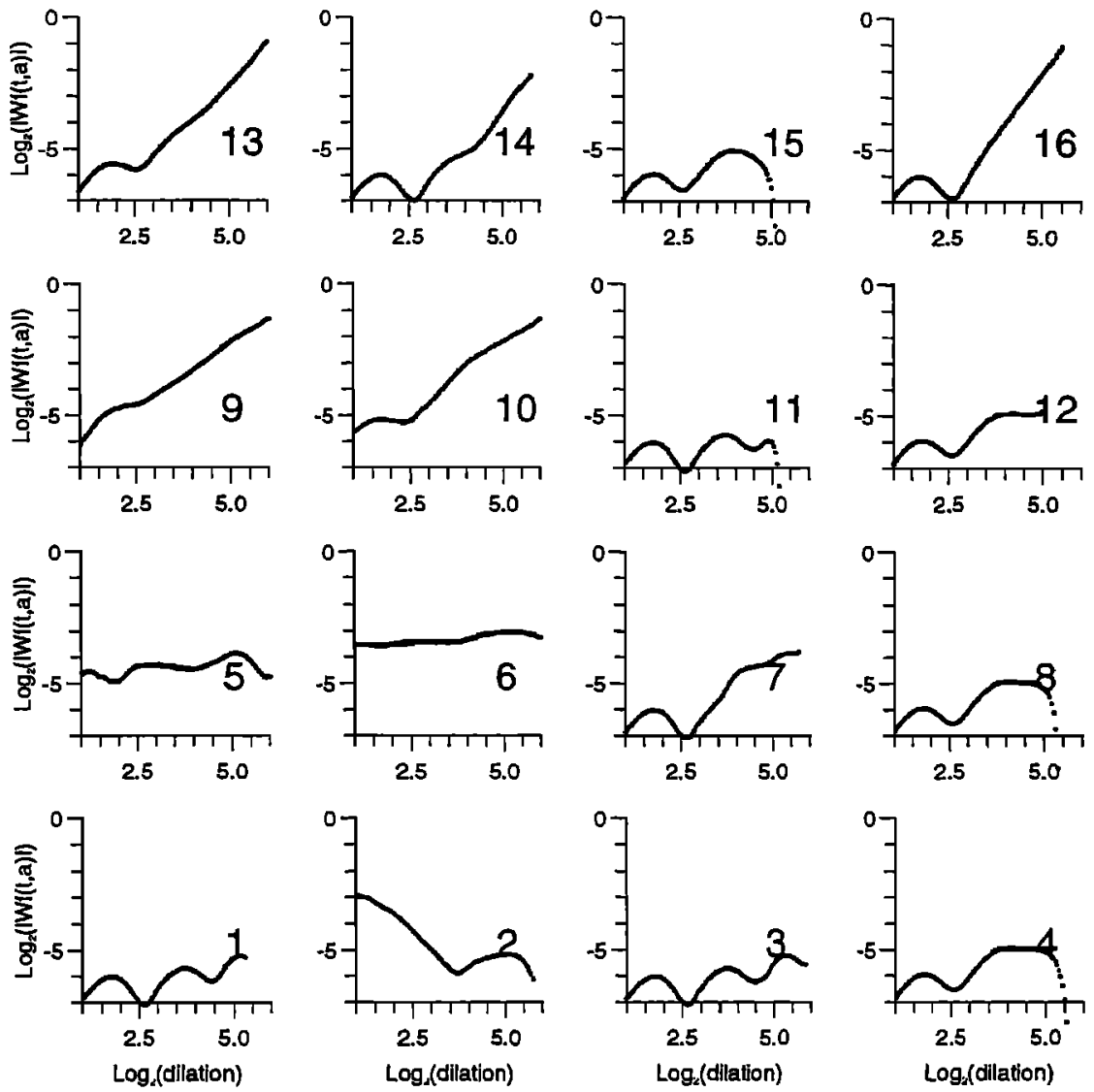

Figure 14. Log-log plots of the ridge functions associated with the labelerl lines of maxima shown on Figure 13. Line 2 is associated with the Dirac singularity, lines 5 and 6 correspond to the Heaviside event, lines 9 and 10 are for the ramp singularity, line 13 is related to the singularity with $\alpha=3 / 2$, and line 16 is associated with the jerk. The slopes found for these lines are $\alpha=-1.29\left(2^{1.4} \leq a \leq 2^{3.5}\right), \alpha=0.11(a \geq 2), \alpha=0.08(a \geq 2), \alpha=0.99\left(a \geq 2^{2.8}\right)$, $\alpha=1.09\left(a \geq 2^{2.5}\right), \alpha=1.42\left(a \geq 2^{2.8}\right)$, and $\alpha=2.01\left(a \geq 2^{2.7}\right)$, respectively.

The influence of a random noise is limited to the small dilations and does not destroy the overall pattern of the ridge functions. This type of ridge functions will be. principally due to the harmonic component.

Type $\mathbf{3}$ is for cases not. clearly falling in either type 1 or 2. This will be especially the case for ridge functions caused by singularities with $\alpha \simeq 0$ (cases 5 and 6 in Figure 14) or by harmonic components (case 3 in Figure. 14). Ridge functions mainly due to the harmonic signal and lacking the characteristic decrease for $a>2^{5.2}$ because of the influence of a nearby singularity are also encountered (cases 7 and 12 in Figure 14). Ridge functions displaying a linear trend with a negative slope (i.e., $\alpha<0$, case 2 in Figure 14, or case 6 in Figure 8) also fall into type 3 since they cannot be safely attributed to either a noisy singularity or to pure noise (compare. cases 1 and 6 in Figure 8).

From a practical point of view, detecting and analyzing a singularity will consist in looking for ridge functions of type 1 and studying its linear portion. As a consequence also, only singularies with $\alpha>0$ can be expected to be recovered.

\section{Real Data Analysis}

We now apply the wavelet analysis to real geomagnetic series. Of course, possible man-made singularities introduced by poor baseline control or poor correction for change of site may also be detected. As we wish not, to confuse them witl geophysically significant events, data series from several independent and nearlby observatories are processed in parallel. We therefore decided to process the data from European observatories only (Figure 15). As the jerks in Europe are particularly clear on the $Y$ (east) component of the field (which is also the component the least affected by the external field) [Courtillot and Le Mouël, 1988; Stewurt, 1991], we shall in this paper focus on $Y$. We shall also put a special emphasis on Chambon-la-Forêt data since we. have easy access to their full history.

\section{Processing of the Chambon-la-Forêt series}

The data series of the monthly mean values of the Chambon-la-Forêt (CLF) geomagnetic observatory span 


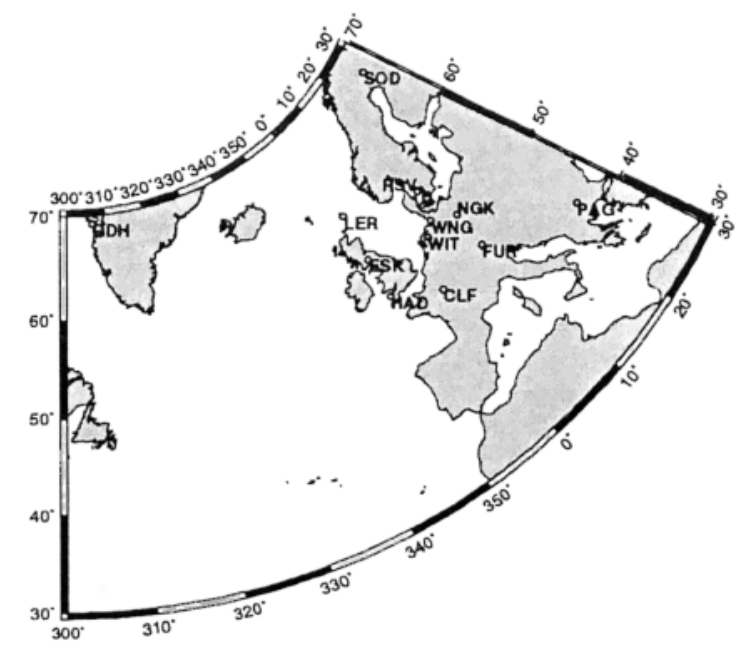

Figure 15. Location of the 12 geomagnetic observatories whose series of monthly mean values of the $Y$ component are used in this study.

a time interval of more than a century (from January 1883 to December 1992; se. Figure 16). Since the beginning of its activities, the observatory moved from the Parc St. Maur (1883-1900) to the Val Joyeux (19011935), and is currently fixed at Chambon-la-Forêt (since. 1935). The whole series has been reset to the Chambonla-Forêt reference level with great care. The monthly means analyzed here are averages of all hourly mean values of each month without any removal of perturbed periods.

The wavelet map (Plate 1, CLF) reveals five conspicuous events of large amplitude for epochs 1901, 1913, 1925, 1969, and 1978 for which jerks have previously been recognized. These jerks have been shown to be worldwide except the one in 1925 which seems to be restricted to the European area [Gire et al., 1984]. Numerous events of smaller amplitude are visible towards the small dilations and arrange themselves into a pattern very reminiscent of the one obtained for the analysis of the synthetic signal made up of harmonic components (Figure 4c). This is particularly clear in the quiet period from 1925 to 1969 where no strong event appears and confirms the results obtained by Kerridge and Barraclough [1985]. Figure 17 represents the 14 lines of maxima which go beyond $a=2^{5}$, and the corresponding ridge functions are displayed in Figure 18 where one can recognize the three basic typical styles discussed in the previous section. Type 1, characteristic: of pure singularities (see ridge functions 4 and 5 in Figure 8), applies to ridge functions $1,2,4,13$, and 14 in Figure 18. Type 2, characteristic of the ridge functions of the synthetic signal made up of harmonic components (Figure 11), applies to ridge functions labelled 3, $5,6,9,11$, and 12 in Figure 18. Type 3 applies to the ridge functions 7,8 , and 10 . Therefore the five strong events which we previously described as being related to published jerks are obviously created by singularities. The slopes of the linear parts of the corresponding

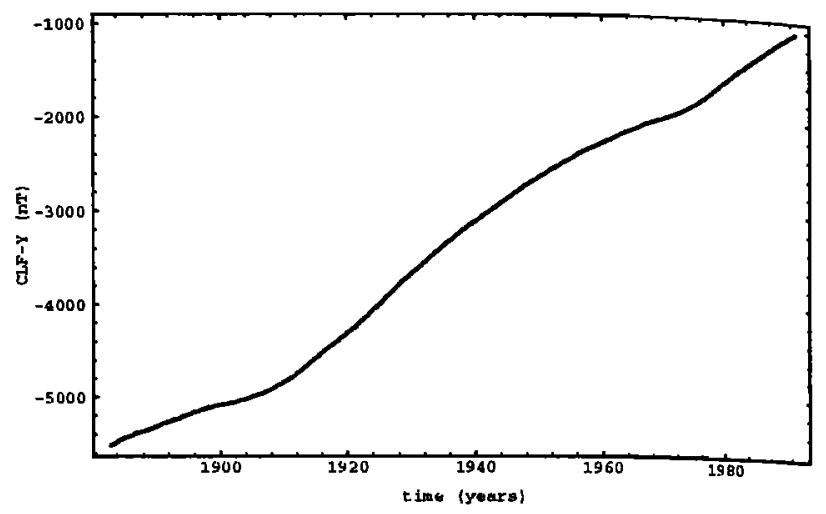

Figure 16. Data series of the $Y$ component for the Chambon-la-Forêt observatory.

ridge functions are well-determined and fall in the interval $[1.47,1.65]$, depending upon the particular ridge function chosen. This important result (to be discussed later) already shows that the detected singularities are not jerks as usually defined (i.e., with $\alpha=2$ ) but, instead, more singular events.

\section{Results for Otler European Observatories}

The monthly mean values of the $Y$ component of the other 11 observatories (Figure 15) considered in this study were provided by the National Geophysical Data Center (Boulder, Colorado) on the compact disk (CDR.OM) labeled NGDC-05/1. For some observatories the data series edited by the World Data Center present. several gaps. In such situations the monthly mean values edited by the observatory itself (e.g., in their yearbooks) were added. (raps for which no clata could be obtained from the yearbooks were filled in by a linear interpolation. No gap longer than 6 months was arcepted. Having maximized both the length and continuity of the timeseries, we noticed that in some instances, corrections to the instrumental baselines were still required. We performed a crossvalidation of the annual mean values computed from monthly means with the annual mean values obtained from the. World Data Center. It appeared that in some cases, corrections for known instrumental changes had been applied to annual mean values but not to monthly mean values. Numerical comparison of the two annual mean data sets allowed the proper corrections to be made. When it appeared that some timeseries would still possibly contain undetected changes in the base level, further information was requested directly from the observatories and used to complete these timeseries.

The wavelet maps of these 11 series are displayed, together with the one corresponding to Chambon-laForêt (CLF) (Plate 1). The common axis scales allow for easy comparison of the pictures, and one can readily check that whenever a data record is long enough, strong events can be found at the same dates as for CLF. A rough dating of the five main events can be obtained by picking the dates along their lines of maxima at the dilation $a=2^{3.5}$, which corresponds to the 

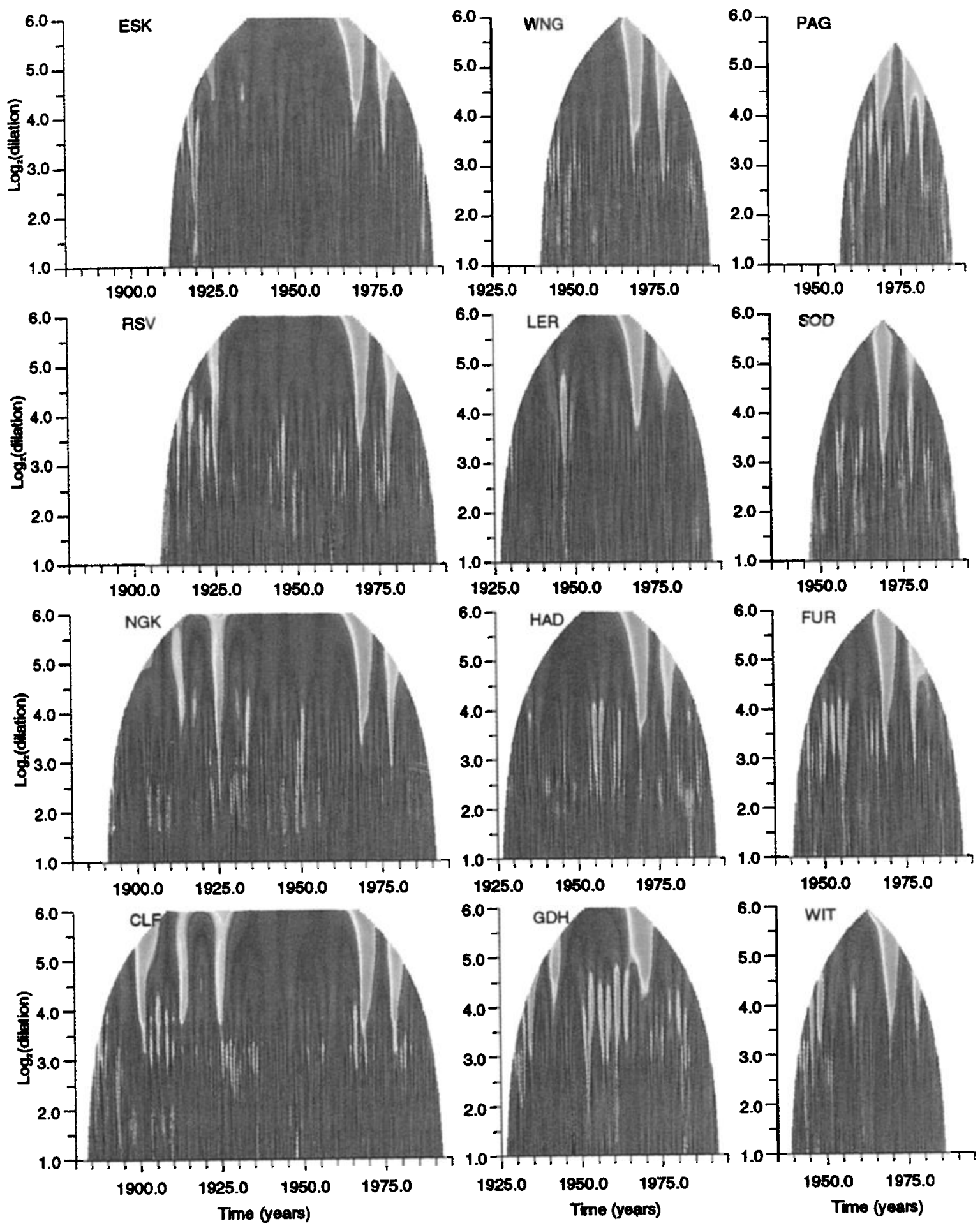

Plate 1. Modulus of the wavelet transform of the $Y$ series for the 12 European observatories: Chambon-la-Forêt (CLF), Eskdalemuir (ESK), Furstenfeldbruck (FUR), Godhavn (GDH), Hartland (HAD), Lerwick (LER), Niemegk (NGK), Panagyurishte (PAG), Rude Skov (RSV), Sodankyla (SOD), Witteveen (WIT), and Wingst (WNG). 


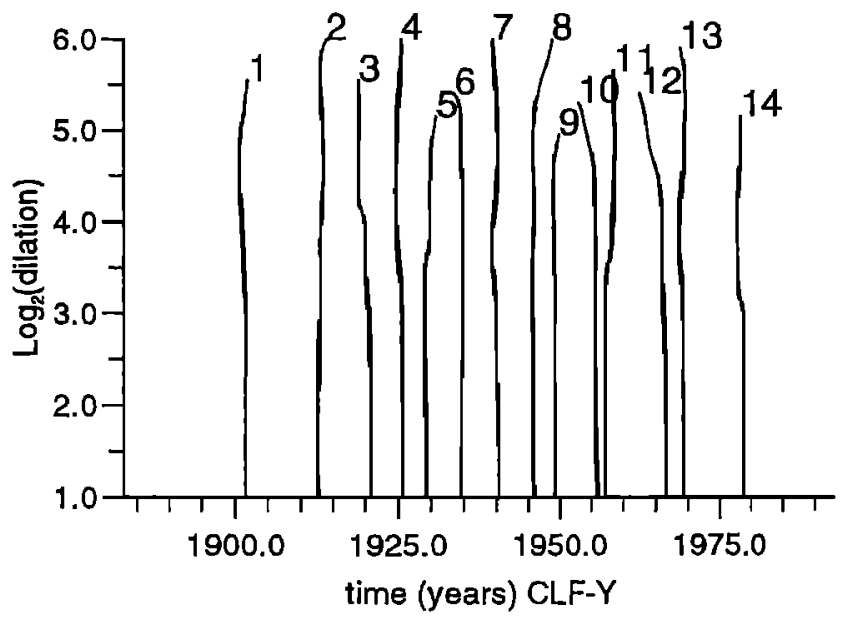

Figure 17. Lines of maxima of the wavelet transform modulus of the Chambon-la-Forêt series slıown on Plate 1, CLF. Only the lines running beyond $a=2^{5}$ are displayed. transition between the part of the ridge function dominated by the external signal and the one controlled by the abrupt changes. Such a criterion gives the following average dates: $1901.3(1), 1913.5(2), 1925.7 \pm 0.72(4)$, $1969.3 \pm 0.38(12)$, and $1978.0 \pm 0.13$ (11) where the \pm value is for one standard deviation and the integers in parentheses indicate the number of observatories used to derive these figures.

The 1901 event detected at CLF cannot be clearly seen at any other observatory because of the shortness of the data series. Only the late edge of an energy packet can be seen in the wavelet maj of the Nienegk series around 1900-1910 and for dilations $2^{4} \leq a \leq 2^{5}$ (Plate 1, NGK).

The 1913 event is clearly found in the CLF and NGK wavelet maps and corresponds to a trumcated one in the RSV wavelet map (Figure 1RSV). The ridge functions for this event are shown in Figure 19 and clearly are type 1. The linear behavior of the ridge function for NGK is excellent beyond $a=2^{2.6}$ and gives a slope $\alpha=1.66$. This linear trend is less perfect for the CLF ridge function which appears more affected by the ex-
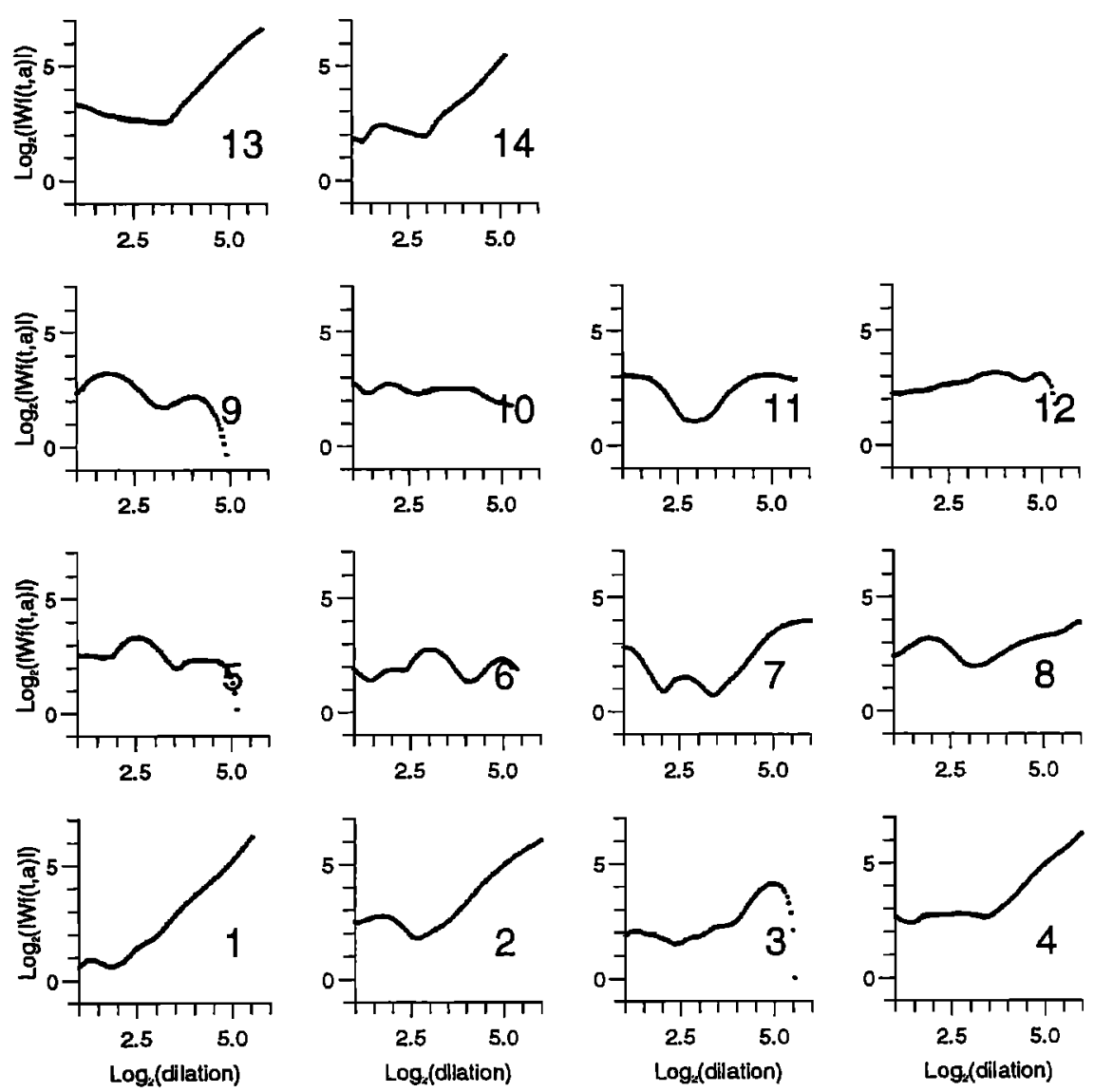

Figure 18. Log-log plots of the ridge functions associated with the labeled lines of maxima shown on Figure 17 and extracted from the wavelet map of the Chambon-la-Forêt data (Plate 1, CLF). The slopes computed for ridge functions $1,2,4,13$, and 14 are $\alpha=1.61,1.47,1.51,1.65$, and 1.60 , respectively, for dilations $a \geq 2^{3.5}$. 

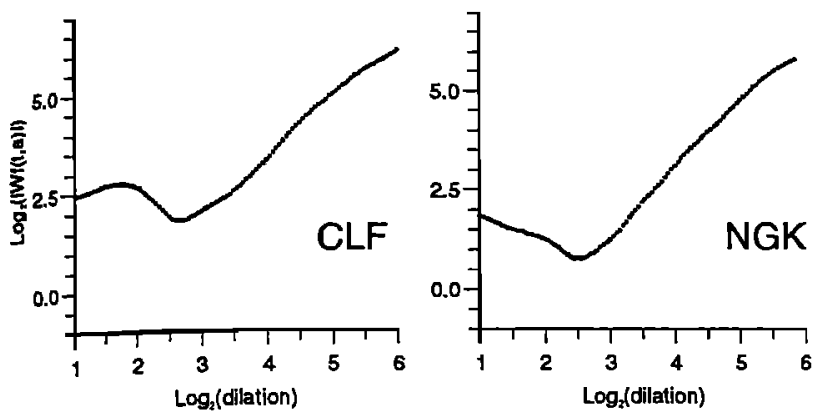

Figure 19. Log-log plots of the ridge functions of the 1913 event found in the Chambon-la-Forêt and Niemegk series. The slopes of the ridge functions are $\alpha=1.44$ for CLF and $\alpha=1.66$ for NGK beyond $a=2^{2.8}$.

ternal component, especially for dilations $a \leq 2^{3}$. The slope, determined for dilations larger than $2^{2.8}$, is less accurately defined and found to be $\alpha=1.44$.

The 1925 event, already known to be regional, is conspicuous on the CLF, ESK, NGK, and RSV wavelet, maps (Plate 1). All corresponding ridge functions are of type 1 (Figure 20) and their slopes are respectively $\alpha=1.51,1.54,1.27$, and 1.20 , respectively, for $a \geq 2^{3.5}$.

The 1969 event is strong and visible in all observatories (Plate 1). The ridge functions displayed in Figure 21 are mutually consistent and of type 1 . The slopes are determined for $a \geq 2^{3.5}$ for an average $\alpha=1.70 \pm 0.07$ (the \pm is for one stanclard deviation) excepted for PAG whose ridge function is not, so clearly linear and has an ill-defined slope $\alpha \simeq 1.40$.

The 1978 event is seen in all observatories but GDH which, despite a sufficiently long record, displays no noticeable event around 1978 (Plate 1, GDH). This problem is likely to be related to the fact that this observatory is located at a high magnetic latitude where disturbances of external origin are strong. The wavelet map (Plate 1, GDH) reveals the presence of an important external contribution during the years around 1980. This may strongly alter an eventual ridge function linked to a singular event in 1978 . The ridge functions, shown on Figure 22, appear to be more disturbed by the external signal than the ones for the 1969 event (Figure 21). This results in a poorer linear behavior of the ridge functions whose slopes fall in the range $[1.08,1.68]$ with an average $\alpha=1.39 \pm 0.17$. However, one should note that the 1978 event falls in the domain of the wavelet maps where the convolutional edge effects are strong and prevent the ridge functions from being tracked beyond dilation $a=2^{5}$ (Figure 22). Of course, future additional data will help make this picture clearer. The present results, however, suggest that a singularity is indeed responsible for the 1978 event.

\section{Discussion and Conclusion}

The aim of the present paper is not so much to "rediscover" the well-known fact that geomagnetic time series have experienced a number of so-called jerks during the present century as to answer a number of doubts and questions that have been expressed about, for instance, the reality and source nature of these jerks. Incleed, making use of wavelet analysis in the way we described brings a number of important and, we believe, convincing answers.

Our wavelet analysis of the geomagnetic series issued by European observatories unambiguously isolates five and only five singularities during the last century: 1901, 1913, 1925, 1969, and 1978. All those events had been previously pointed out using more classical technicues, although in an heterogeneous and sometimes debatable way. In contrast, the present analysis is carried ont homogeneously and without the help of any a priori information. The more subtle possibility of sharpening the jerk with some additional external signal carı also be discarded. This reinforces the notion that jerks are of an internal nature. Indeed, all singularities detected in the geomagnetic series show ridge functions whose linearity extends from time constants of the order of 2 years till time constants of decades. Such a constant value of the slopes for this whole range of scales establishes that these events are due to a single coherent source. One can hardly believe that the detected events could possess an accurate self-similarity resulting systematically and by chance from a sharp external variation superimposed on a smoother internal one. The lack of linearity of the ridge functions for time constants shorter than 2 years can be interpreted in view of the study that was carried out with the synthetic harmonic signal. It shows that the strong annual harmonic component controls most of the ridge functions in the small-dilation range (compare for instance Figures 14 and 21) which also happens to be most sensitive to noise. The signal eventually created by the singularity at small dilations is therefore hidden. Thus the singularities we detected definitely occur in less than 2 years.

A last interesting result is that the events are more singular than jerks (with the retained acceptance of the
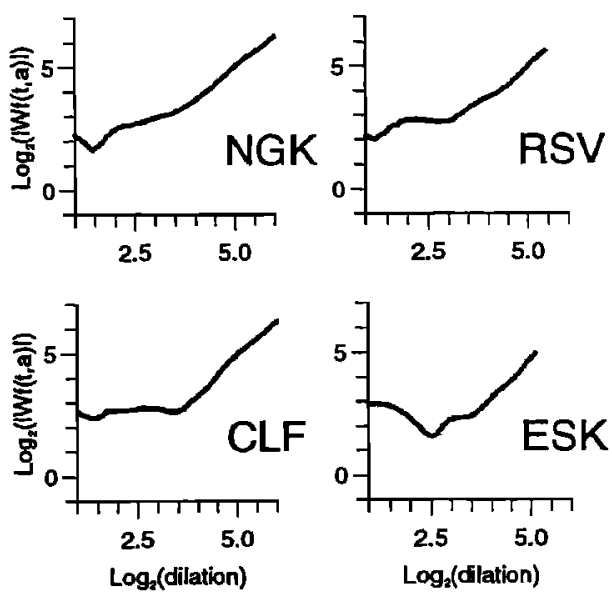

Figure 20. Log-log plots of the ridge functions of the 1925 event. The slopes calculated for CLF, ESK, NGK, and RSV are $\alpha=1.51,1.54,1.27$, and 1.20 for dilations $a \geq 2^{3.5}$. 

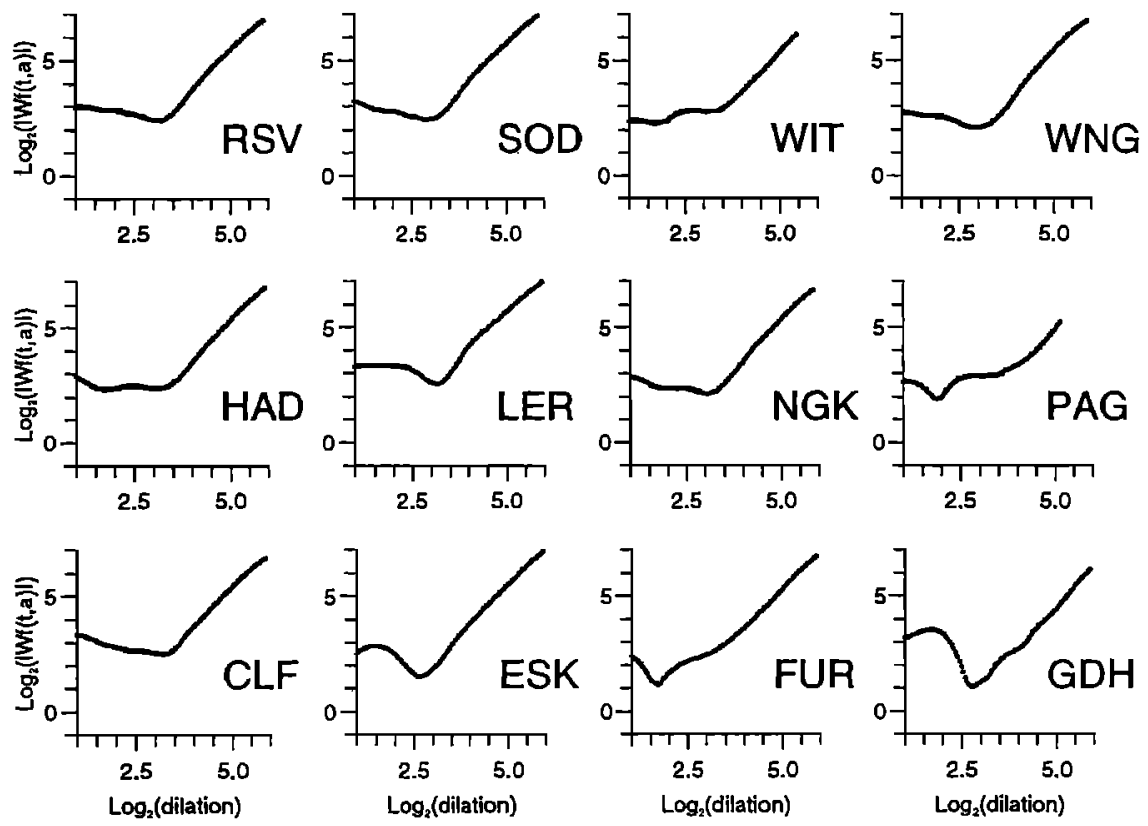

Figure 21. Log-log plots of the ridge functions of the 1969 event found in the 12 European observatories used in this study. The slopes clerived for dilations $a \geq 2^{3.5}$ and for the observatories listed in alphabetic order are $\alpha=1.65,1.65,1.64,1.72,1.77,1.56,1.76,1.39,1.69,1.65,1.70$, and 1.82 .

term for which $\alpha=2$ ). Although the regularities $\alpha$ are not determined with a very high accuracy, this accuracy is good enough to show that the $\alpha$ are always significantly less than 2 and usually close to the value. 1.5. When applied to the synthetic signal, the analysis brings the practical results for $\alpha$ (see Figure 14) of $1.29,0.11,0.08,0.99,1.09,1.42$, and 2.01 instead of the theoretical values $-1,0,0,1,1,1.5$, and 2 . These tests indicates that regularities $\alpha \in[1 ; 2]$ are determined with a relative uncertainty of about $10 \%$. Jerks are more subtle singularities than previously thought, and previous studies will probably have to be resumed (parabola replaced by noninteger power of $t-t_{E}, t_{E}$ being the time of the event), and any new study will have to take
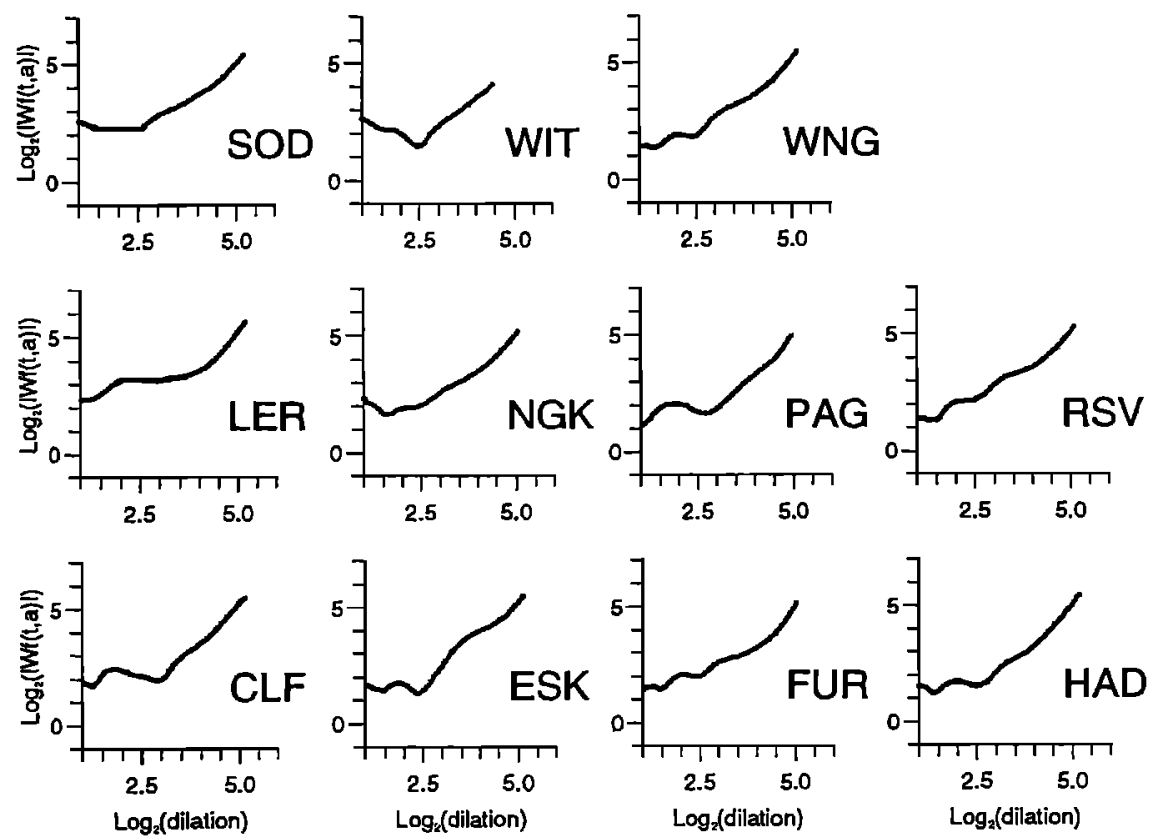

Figure 22. Log-log plots of the ridge functions of the 1978 event found in 11 European observatories used in this study. The slopes, computed for $a \geq 2^{3.5}$, are $\alpha=1.58,1.08,1.47,1.68,1.42$, $1.37,1.50,1.29,1.26,1.21$, and 1.41 . 
this result into account. One can first think of studies in the spirit of the one carried out by Backus [198:3], which assumes that the observed characteristics of the jerks are the result of a rather pure core signal distorted by the slightly conducting mantle; an approach that can lead to a number of interesting constraints for the value. of the conductivity within the mantle [e.g., Ducruixi et al., 1980; Achache et al., 1980, 1981; Courtillot et al., 1984]. Recent high-pressure measurements lead to very low estimates for the mantle conductivity [Peyronnean and Poirier, 1989; Poirier and Peyronneau, 1992] and strongly suggest that a second approach to the jerks should be developed. The observed characteristics of these jerks could very well be a direct consequence of the mechanisms that are responsible for them within the core [Le Mouell and Courtillot, 1981, 1982]. The sulbject is of crucial importance for the clynamo theory, and recent studies suggest that jerks cannot, be considered inclependently from the rest of the mechanisms generating the Earth's main magnetic field. For instance, Jault and Le Mouel [1994] have shown that jerks cannot be created by superficial flows, and Hulot et al. [1993] have given evidence that jerks could be related to major changes within the large-scale flow driving the core convection. Our results could shed some light on this global convection. The present study was limited to the $Y$ component in European observatories as it was specially easy to handle and allowed a safe cross-checking. Analysis needs to be extended to other components and other observatories to assess the worldwide character of the events. A better estimate of the date of the events all over the Earth must be obtained to study a possible propagation of the events and understand its origin.

Acknowledgments. We are pleased to thank the staffs of the geomagnetic observatories for their kind supplying of high-quality data. This work benefited from numerous discussions with Alex Grossmann, Matthias Holschneider, and Jean Morlet. Associate Editor Robert A. Langel and three anonymous referees made very constructive reviews. Most. computations were done using the computational facilities operated by the Centre des Ressources Informatiques from Université de Rennes 1, and we thank Jean-Pienre Boulard. François Dagorn, and Eric Picheral for their teclmical support. This is IPGP contribution 1345.

\section{References}

Achache, J., V. Courtillot, J. Ducruix, aucl J.-L. Le Monël, The late 1960's secular variation jmpulse: furtlier constraints on deep mantle conductivity, Plys. Earth Planet. Inter., 23, 72-75, 1980.

Achache, J., J.-L. Le Mouël, and V. Courtillot, Long-period geomagnetic variations and mantle conductivity: An inversion using Bailey's method, Geophys. J. R. Astron. Soc., 65, 579-601, 1981.

Alldredge, L.R., A discussion of impulses and jerks in the geomagnetic field, J. Geopluys. Res., 89, 4403-4412, 1084. Argoul, F., A. Arnéodo, G. Grasseau, Y. Gagne, E.J. Hopfinger, and U. Frisch, Wavelet analysis of turlbulence reveals the multifractal nature of the Richardson cascacle, Nuture, $338,51-53,1989$.
Backus, G.E., Application of mantle filter theory to the magnetic jerk of 1069, Geophlys. J. R. Astron. Sor., 7., 71:3746, 1983.

Backus, G.E., and S. Hough, Sume morlels of the geoungnetic field in western Europe from 1960-19\%0, Plhys. Eurth Planet. Inter., 39, 243-254, 1985.

Backus, G.E., R.H. Est,es, D. Chinn, and R.A. Langel, ('unparing the jerk with other global models of the geomagnetic field from 1960 to $197 \times, J$. Geophyss. Re's., 92, 3615$3622,1987$.

Bacry, E., A. Arméodo, U. Frisch, Y. (iagne, and E.I. Hopfinger, Wavelet analysis of fully developped t.mbinlence clata and meawienent of sicaling exponents, in Turbulence and Coherent Structures, edited hy M. Lestem and O. Métajs, pp. 203-215, Ḱluwer Acaclemic, Nol'well, Mass., 1991.

Bloxham, J., D. Gublins, and A. Jackson, (ieomagnetic: secrular variation, Philos. Traths. R. Soc:. Lotulon A, 5289, 415-502, 1989 .

Chau, H.D., J. Ducruix, aud J.-L. Le Mouël, Sur le cauactìre planétaire du saut de variation séculaire cle 19)(90-1970, 6 : R. Acad. Sci. B, 293, 157-160, 1981.

Courtillot, V., and J.-L. Le Mouël, On the long periud variations of the Earth's magnetic field from 2 moutlis to 20 years, J. Geophys. Res., 81, 2941-2050, 1976 (ja.

Courtillot, V., and J.-L. Le Monël, Time variations of the Earth's magnetic field with a period lunger than two months, Plays. Eurth Planet. Inter., 122, 2:37-240, 197 (ch).

Courtillot, V., and J.-L. Le Mouël, Time variationss of the Earth's magnetic field: From daily to secular, Annu. Re't). Earth Planet. Sci., 16, 3\$?-476, 1943.

Courtillot, V., J. Ducruix, anel J.-L. Le Monël, Sux une: accélération récent.e de la variation séculaire du clıamp nuagnétique terrestre, $C . R$. Ac:al. Sci. $D$, 287, 1095-1095, 1978.

Courtillot, V., J.-L. Le Mouël, aud J. Ducıuix, On Backıs' mantle filter theory and the 1969 geomagnetic impulse, Geophys. J. R. Astron. Soc., 78, 619-625, $19 \$ 4$.

Currie, R.G., The geomagnetic spectrum 40 days to 5.5 years, J. Geophys. Res., 71, 4579-450s, 1906.

Currie, R.G., Geomagnetic spectinun of internal urigin and lower mantle conductivity, $I$. Ge'oplkys. Res., 7\%, 277?)2786, 1968.

Daubechies, I., Ten Lectures on Waveletss, C:BMSS Str. Appl. Math., vol. 61, Society for Industrial aurd Applied Mat.lematics, Philadelphia, Pa., 1992.

Ducruix, J., V. Courtillot, and I.-L. Le Monël, The latie 1960's secular variation impulse, the eleven year magntetic. variation and the electrical conductivity of the deep mantle, Geophys. J. R. Astron. Soc., 61, 73-94, $10 \times 0$.

Fisk, H.W., Magnetic secular variation and solar activity, Int. Res. Counc. Comm. Sol. Terrest. Relution. Rep., 3, 52-59, 1931.

Gavoret, J., D. Gibert, M. Menvielle, and J.-L. Le Muuël, Loug-term variations of the exterual and internal components of the Earth's magnetic field, J. Geoplyys. Re's., 91, 4787-4796, 1986.

Gel'fand, I.M., and G.E. Sliilov, Les Distributions, Dumoel, Paris, 1962.

Gire, C., J.-L. Le Mouël, and J. Ducruix, Evolution of the secular variation field from the begiming of the century, Nature, 907, 349-352, 1984.

Golovkov, V.P., T.I. Zvereva, and A.O. Simonyau, Common features and differences between "jerks" of 1947, 195א and 1969, Geophys. Astrophys. Fluill Dyn., 4!9, 81-!)(, 1!98!).

Goupillaud, P., A. Grossmann, aunl J. Morlet, ('ycle-crtave and related transforms in seismic signal analysis, Geot: ploration, 23, 85-102, 1944.

Grossmann, A., Wavelet, transform aud edge detection, in Stochustic Processes in Physic's and Engineterinul, edlited 
by M. Hazewinkel, Ip). 149-157, D. Reiklel, Norwell, Mass., 1986.

Grossnamn, A., and J. Morlet, Decomposition of Hardy functions into scplare integrable wavelet.s of constaut, shapes, SIAM J. Math. Anal., 15, 7233-7336, 1984.

Grossmanm, A., M. Holschueicler, R. Kúroulaukl-Martiuet, and J. Morlet, Detection of alorupt cluanges in sound signals with the lielp of wavelet, transforins, in Inverser Prollems: An Interclisciplinary Sturly; Adv. Elertr. Elertor. Phys., Supp. 19, pP. 20\%-306, Acalemic, Sau Diego, Calif., 1987.

Gubbins, D., Geomagnetic, field analysis, II, Secular varjation consistent with a perfectly conclucting core, (iespluys. J. R. Astron. Soc., 77, 7533-760, 1944.

Gubbins, D., and L. Tomlinsom, Secular variation from monthly means from $A_{1}$ ia and Amberley maguetic ol)servatories, Geophys. J. R. Astron. Soc., 86, (i013-6ili, 1986.

Hulot, G., M. Le Huy, and J.-L. Le Moül, Secuussess (jerks) de la variation séculaire et. mouvenuents daus le noyau t.erlrestre, $C^{\prime}$. R. Accul. Sci., St:r. II, :317, 3333-341, 19933.

Jault, D., and J.-L. Le Monël, Dotss secular variation involves motions in the deep core?, Pliys. Eurth Plane't. Inter., 82, 185-193, 1994 .

Kerridge, D.J., and D.R. Barraclough, Evidence for geomatgnetic jerks from 19:31 to 1971, Plays. Eurth Plunct. Intetr, 39, 228-236, 1985.

Langel, R.A., The main geomagnetic fielkl, in Geomaynctism, vol. 1, edited by J.A. Jacolss, pl?. 249-492, Acadenic, Sall Diego, Calif., $19 \$ 7$.

Le Mouèl J.-L., and V. Courtillot, On the outer layreis of the core and the geomagnetic secular variation, J. Geopllyss. Res., 87, 4103-4108, 1982.

Le Mouël, J.-L., J. Ducruix, and H.D. ('han, The worlelwicle cliaracter of the 1960-1970 inusulse of the secular accelluation rate, Phys. Eurth Plumet. Intere, 28, 337-350, 195:2.

Le Mouël, J.-L., aud V. Couttillot, ('ore mutions, electromagnetic core-mantle coupling and variations in the Earth's rotation: new constraints from geomagnetic. secular variation inpulses, Physs. Eurth Plankt. Inter., ash, 236-241, 1981.

Malin, S.R., and B.M. Hodcler, Was the 1970 geomagnetic jerk of internal or external origin?, Naturt, 2.96, $72(i-724$, 1982.

Malin, S.R., B.M. Hodder, and D.R. Barraclough, Geomagnetic secular variation: A jerk in 1970, in 75th Anniver- sary Volume of Ebro Observatory, edited by J.O. Carchus, pp. 239-256, Roquetes, Tarragona, Spain, 19\$3.

Mallat, S., and W.L. Hwang, Singularity detection and processing with wavelets, IEEE Truns. Inf. Theory, 38, 617643, 1992.

McLeod, M.G., On the geomagnetic jerk of 19G9, J. Girophys. Res., 90, 4597-4610, 1985.

McLeod, M.G., Signals and noise in magnetic olsservatory annual means: Mantle conductivity and jerks, J. (itophys. Res., 97, 17261-17290, 1922.

Meyer, Y., Ondelettes et opéruteurs, 343 pl', Hermaun, Paris, 1990.

Muzy, J.F., E. Bacry, and A. Armeodo, Wavelets and unultifractal formalism for singular signals: Applicatijon to turbulence data, Phys. Rev. Lett., 67, 3515-351\%, 1901.

Nevanlinna, H., On extermal and interual parts of the geomagnetic jerk of 1970, Phys. Enrth Planet. Inter., 39, 265-269, 1985.

Peyronneau, I., and J.-P. Poirier, Electrical couductivity of the Earth's lower mantle, Naturt, 34.2, 5337-53!), 1989).

Poirier, J.-P., and J. Peyronmean, Experinental determination of the electrical couchuctivity of the material of the Eartli's lower mantle, High-Pressisure: Resserurrla: Applirutions to Earth and Plunet. Scientet, Geophyss. Monoxyr. Ser., vol. 67 , edited by Y. Syono aud M.H. Maugluna, pp. 77-87, AGU, Wasliugtou, D.(., 1902.

Stewart, D.N., Geomagnetic impulses aud the electrical coulductivity of the lower mantle, Pl..D. thesis, 191 1'p., Dep. of Eartli Sci., Univ. of Leecls, Leecks, England, 19?91.

Stewart, D.N., and K. Whaler, ('eomagnetic: disturlyance fields: An analysis of olsservatory monthly neass, (jeo. phys. J. Int., 108, 215-223, 1992.

M. Alexandrescu, G. Hulot, aud J.-L. Le Moü̈l, Institut. de Plyysique du Globe, B.P. 89, 4 Place Jnssien, 75,252 Paris cedex 5, France. (e.mail: mioara(ojpgr.jussien.fi; htlot.@ipgp.jussieu.fr; lemouel(tipgr.jussieu.fi)

D. Gibert, and G. Saracco, Ćéosciences Remues, Université de Renmes 1, Bât. 15 Campus de Beauliẹl, 35042 Remues cedex, France. (e.mail: gibert,(1)muiv-1'umesilfr; ginet@univ-rennes1.fr)

(Received July 6, 1994; revisedl January 17, 1995; accepted January 26, 1995.) 